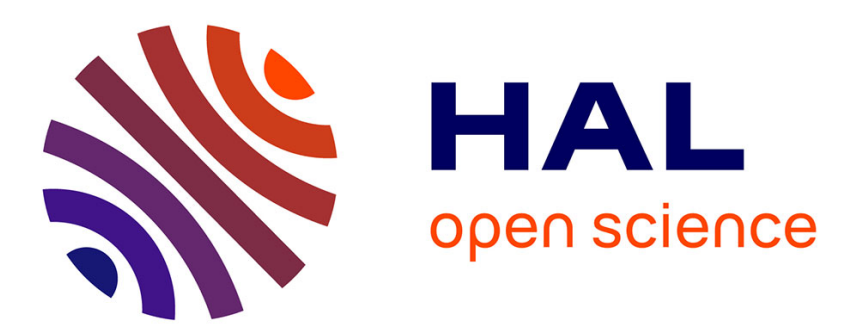

\title{
Insert of sandwich panels sizing through a failure mode map
}

Juan de Dios Rodríguez Ramírez, Bruno Castanié, Christophe Bouvet

\section{To cite this version:}

Juan de Dios Rodríguez Ramírez, Bruno Castanié, Christophe Bouvet. Insert of sandwich panels sizing through a failure mode map. Composite Structures, 2020, 234, pp.0. 10.1016/j.compstruct.2019.111724 . hal-02952824

\section{HAL Id: hal-02952824 \\ https://hal.science/hal-02952824}

Submitted on 29 Sep 2020

HAL is a multi-disciplinary open access archive for the deposit and dissemination of scientific research documents, whether they are published or not. The documents may come from teaching and research institutions in France or abroad, or from public or private research centers.
L'archive ouverte pluridisciplinaire HAL, est destinée au dépôt et à la diffusion de documents scientifiques de niveau recherche, publiés ou non, émanant des établissements d'enseignement et de recherche français ou étrangers, des laboratoires publics ou privés. 


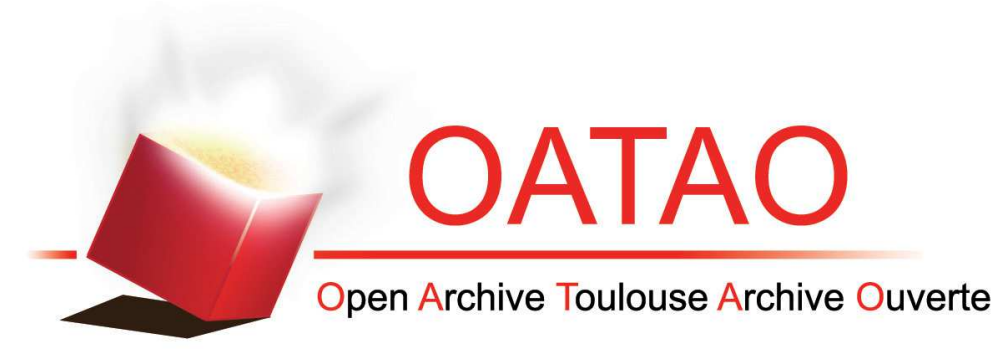

\section{Open Archive Toulouse Archive Ouverte (OATAO)}

OATAO is an open access repository that collects the work of some Toulouse researchers and makes it freely available over the web where possible.

This is an author's version published in: https://oatao.univ-toulouse.fr/26730

Official URL:https://doi.org/10.1016/j.compstruct.2019.111724

\section{To cite this version :}

Rodríguez Ramírez, Juan de Dios and Castanié, Bruno and Bouvet, Christophe Insert of sandwich panels sizing through a failure mode map. (2020) Composite Structures, 234. ISSN 0263-8223

Any correspondence concerning this service should be sent to the repository administrator: tech-oatao@listes-diff.inp-toulouse.fr 


\title{
Insert of sandwich panels sizing through a failure mode map
}

\author{
Juan de Dios Rodríguez-Ramírez, Bruno Castanié*, Christophe Bouvet \\ Institut Clément Ader (ICA), Université de Toulouse, CNRS UMR 5312-INSA-ISAE-SUPAERO-Mines Albi-UPS, Toulouse, France
}

\begin{abstract}
A B S T R A C T
Inserts of sandwich panel joints are commonly sized using analytical approaches that provide a rough estimation of the pull-out strength. In this investigation, the use of failure mode maps is proposed as an alternative to the conventional methods. These failure charts are created by means of several advanced nonlinear numerical simulations that can provide accurate pull-out strength estimations. This technique may require a considerable investment of time and effort but, in exchange, it could reduce the time and cost of insert design in the long term.
\end{abstract}

Keywords:

Inserts

Potting

Failure mode map

Sandwich structures

\section{Introduction}

The aeronautical sandwich structure consists of three main elements: two thin, stiff, strong faces and a thick, light, weak core, often made of Nomex honeycomb. While the faces support the in-plane forces, the core keeps them a certain distance apart, increasing the inertia and consequently the bending stiffness, which can be significantly higher than that of heavier laminate sheets. Because of their light weight, these panels are of special interest for aeronautic and aerospace applications [1] and they are used for the main body of helicopters or some business jets like the Beechcraft Starship [2,3] or the Raytheon Premier I. Nevertheless, despite their great advantages, for commercial aircraft, they are restricted to secondary structures such as doors, cabin interiors and control surfaces like ailerons, spoilers, etc. [4,5]. The reason for this is that they are not yet well mastered in terms of manufacture, fatigue, damage growth, debonding, assembly, impacts, etc. Sandwich structures are often joined by means of inserts, which are local densifications that raise the core strength, providing the panel with a section where one or many junctions can be installed. This type of assembly is by far the most used for sandwich panels because is simple and, most of the time, handmade, which guarantees low costs. For low load carrying junctions, an insert consists of a metallic threaded fastener that is installed, bonded and sealed into the sandwich panel by injecting adhesive around it; this adhesive is often called potting [6].

\subsection{Overview of analytical approaches for insert sizing}

The size and the material of the densified section must be selected to resist the joint loads. There are several methods available to analyze the stress distribution in the vicinity of the insert, which allow a size to be determined for it. The analysis performed by Bozhevolnaya et al. in [7] or that proposed by Thomsen in [8]. The latter uses the high-order sandwich panel theory (HSAPT) to accurately estimate the stress distribution in the core and skins. The most widely used approach is still the one proposed by the U.S. Forest Product Laboratory in 1953 [9], which was adopted by the European Space Agency (ESA) in the first insert design handbook or the most recent ECSS-E-HB-32-22A Insert Design Handbook [10] and is also the basis of the modified direct shear approach of Military Handbook 23-A [11]. Finally, the simplest of all is the direct approach by simple shear. Typically, these analytical methods can be implemented quickly.

However, in practice, the pull-out strength estimated by means of the most common analytical approaches often differs from the experimental results $[12,13]$. To better illustrate this, an overview of the accuracy is given in Fig. 1. A compilation of several pull-out tests of panels with Nomex honeycomb core performed by several researchers were used as experimental evidence (see Table 5 in annex for more details) and the experimental pull-out strengths are compared to the estimations obtained by means of the ESA approach, the military handbook 23-A method and the direct shear approach. The estimations using the ESA method (red bars) are the closest to the experimental results (blue bars), followed by the estimations based on MIL-HBK 23A (which are very similar to those found with the ESA method) and, finally, the least accurate are predicted by the simple shear approach.

Nevertheless, the accuracy of the ESA estimations is very irregular. For some cases the error is between $7.5 \%$ and $20 \%$ (see comparison of the cases of Heimbs, Kumsantia or Song in Fig. 1, for example), which could be considered acceptable; for some others the error is in the \pm $50 \%$ range, which is considerable (see cases of Roy, Bunyawanichakul or Yong-Bin Park in Fig. 1 for example). This lack of accuracy of the analytical methods could be explained by the accumulation of errors related to insert manufacturing, the testing procedure and the

\footnotetext{
* Corresponding author.

E-mail address: bruno.castanie@insa-toulouse.fr (B. Castanié).
} 


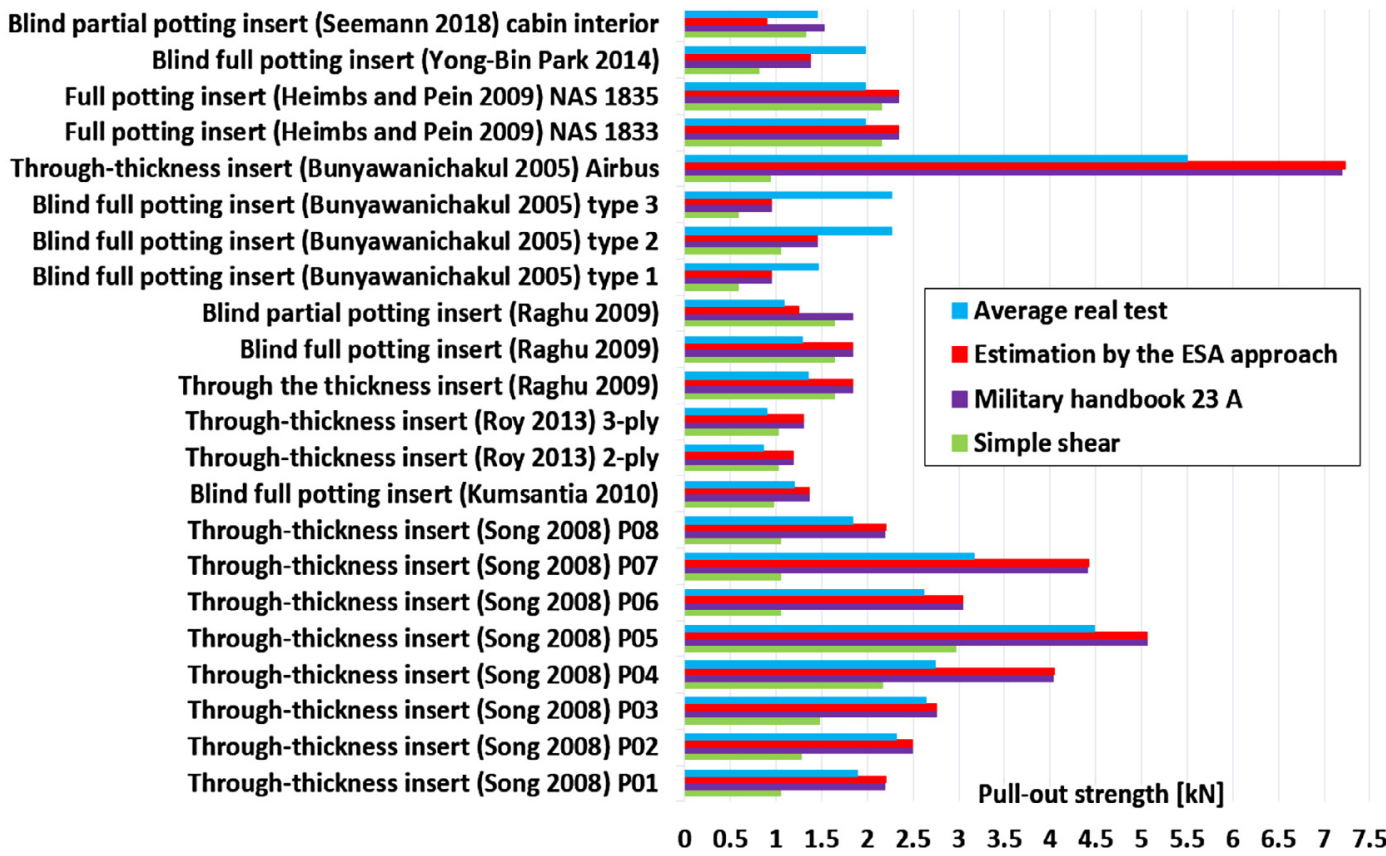

Fig. 1. Comparison of the experimental and pull-out strengths and those estimated using the most common analytical approaches [14-22].

analytical calculation method.

From the manufacturing point of view, since inserts are handmade, they are typically full of defects that are not introduced on purpose and which are therefore difficult to predict or quantify.

From the experimental point of view, another source of error might be that there are different methods to identify the insert strength. The most common consist in identifying the end of the linear behavior of the force vs displacement curves, i.e. searching for a change in the slope. In general, a variation of $1 \%, 2 \%$ or $5 \%$ is used to detect the end of the linear behavior, and thus, the "structural failure" of the insert $[20,23]$. Also, there are some references that identify the insert pull-out strength in the first peak of the force vs displacement curve [14,15,22,24]. Although both approaches are based on the insert stiffness, they identify different points and, thus, different pull-out strengths. Finally, there are few references that identify the insert strength when the first component starts to be damaged or plasticizes $[25,26]$. According to the related literature, this is mostly the honeycomb core. Yet, identifying the exact moment when a honeycomb structure fails can be a very subjective enterprise since, at the beginning of the nonlinear shear behavior, it mostly works in a reversible postbuckling regime, and its overall structural behavior could remain elastic even if the cell walls start to plasticize locally as shown in [27]. To state the problem briefly, it is difficult to identify the actual experimental pull-out strength and subjectivities inevitably introduce some error.

Finally, from the calculation point of view, another cause could be the actual accuracy of the analytical approaches used to estimate the pull-out strength. This aspect has been addressed by Wolff et al. in [13] where they show that the predicted pull-out strength, calculated using the ESA approach, does not accurately follow the strength trend of the experimental results. This can also be seen in the study by Song et al. [22]. In their research, they evaluated the influence of the variation of the core height, the stacking sequence and skin thickness, and the core density. If the experimental results are compared to the estimations obtained through the ESA approach (see Fig. 2 for the variations of core height, skin thicknesses and core density), the shapes of the envelopes of the experimental and the calculated failure loads differ considerably, especially for the skin thickness and core density variations.

Another problem with the accuracy of the analytical method used by ESA is the fact that it relies on several coefficients to include some considerations, such as the different shear moduli in the $\mathrm{W}$ and $\mathrm{L}$ directions, the maximum and minimum potting size for a given insert diameter, the correction factor of the shear strength depending on the height correction, or even whether a homogenized shear modulus is considered for the core. This aspect is relevant because, if an aspect of the joint is not clear and the coefficients are not chosen correctly, the calculation of the failure load might be wrong (see Fig. 3). Wolff et al. [28] used ESA's analytical approach for the validation of an insert and presented a very detailed review of the existing coefficients and assumptions that can be applied when using this approach. They had to choose between two mathematical formulations for the insert strength, 6 different coefficients to correct the shear strength of the core, 4 homogenization methods for the shear moduli of the core, and 4 different models to consider the variations of the potting radius. Even so, they indicated in their conclusions that there was a considerable difference between the final estimation and the experimental pull-out strength. It is also worth mentioning that the inclusion of coefficients in an analytical approach reduces its physical meaning. An example of this can be found in the ESA insert design handbook, which relates the failure of the core under damage in both the $\mathrm{W}$ and $\mathrm{L}$ directions and states that, due to the percentage of single foils in both directions, an equivalent shear strength should be used instead, which must be calculated by multiplying the shear strength of the $\mathrm{W}$ direction by a factor of 1.36. The book does not give any more details about how this coefficient is obtained. From our research, reported in [27], we found experimental evidence suggesting that the shear strength of a Nomex honeycomb core can be increased by $16 \%$ to $35 \%$ depending on the boundary conditions. This happens because the stresses in the cell walls near an insert are better distributed because of the extra stabilization provided by the potting. The authors believe that that it might be very simplistic to reduce such complex phenomena to a simple fixed coefficient (the shear strength depends on the coupled postbuckling behavior of the Nomex honeycomb structure, so the shear strength changes if defects and/or the boundary change).

\subsection{Overview of the numerical approaches for insert sizing}

Another approach to estimate the pull-out load of inserts is through F.E. modeling. According to several authors, this approach could 

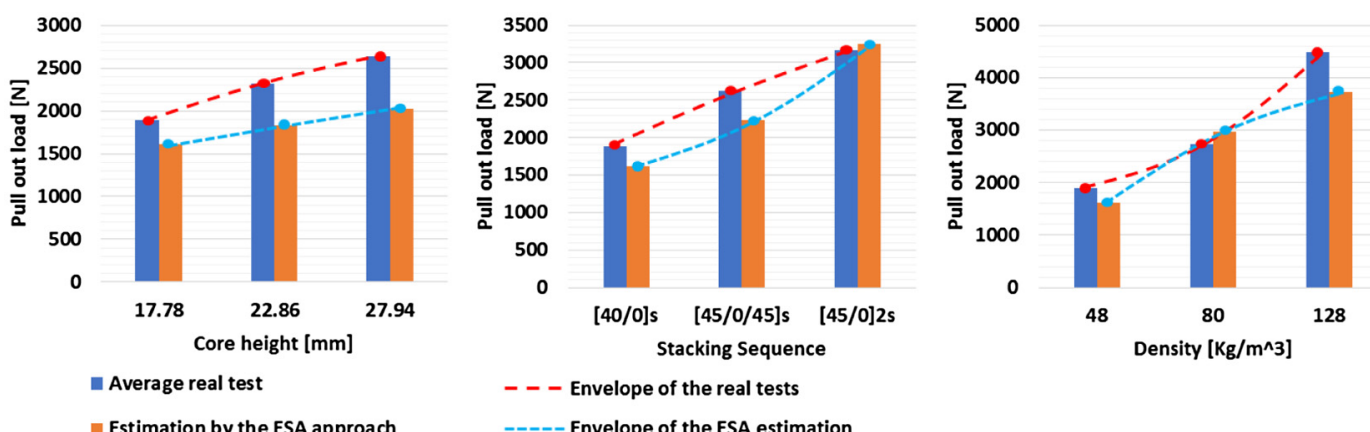

Estimation by the ESA approach

------ Envelope of the ESA estimation

Fig. 2. Comparison of the experimental and calculated pull-out strengths of the pull-out tests performed by Song et al. [22]. The ESA and the experimental tests have different tendencies.

provide a better estimation than the analytical approaches $[4,6,17]$. This method may offer several serious advantages, since it makes it possible to understand how inserts fail, the order in which the parts start to break and which failures are the most critical. It also allows the influence of some defects to be included and evaluated. Nevertheless, there are some disadvantages: modeling the core and the real potting shape demands considerable expertise and a heavy time investment.

In 2015, this approach was used by Seemann et al. for the virtual testing of inserts $[28,29]$. First, they focused on the modeling of honeycomb cores [30,31] before developing a detailed model of an insert pull-out test. At the end, the results showed consistent agreement with the experimental results and they could reproduce the insert pull-out post-failure behavior, which is quite an achievement considering the complexity of the problem. Nevertheless, it may prove complicated to perform this kind of analysis every time an insert needs to be designed. Also, considering the geometry of the honeycomb cells and all the possible potting shapes, it might be necessary to perform one simulation for each possible potting configuration, which is not practical. All in all, the main limitation of insert sizing through F.E. modeling is the development time and the expertise required. A detailed model can deliver very accurate estimations but the time investment can be high to the point of not being viable. On the other hand, a very rough model might not deliver accurate estimations.

\subsection{Insert sizing through virtual testing and failure mode maps}

To sum up all these considerations, analytical methods can be rapidly implemented but the accuracy of the predictions could be questionable, and they also rely on the correct choice of coefficients. In contrast, the development of F.E. models may give more accurate estimations but the expertise required and the time invested are not very encouraging. From a practical point of view, both methods present several advantages and disadvantages. For example, the ESA method implements a statistical approach to consider the different potting shapes within an equivalent minimal, typical or maximal value of the potting radius, which allows the number of calculations to be reduced. For the F.E. approach, the main advantage is the accuracy of the predictions.

In the present research, the advantages of both methods are combined to draw a failure mode map of inserts subjected to pull-out loading. The idea is to use these failure maps as tool for the rapid sizing of inserts. First, an F.E. model of an insert pull-out test is developed and validated through experimental tests. This model is not as detailed as the models developed by Roy et al. in [20], Seeman et al. in [14,31] or Slimane et al. in [32]. Instead, several simplifications proposed by ESA in [10] and the ideas and results presented previously in [27,33] are considered. These simplifications reduce the development and

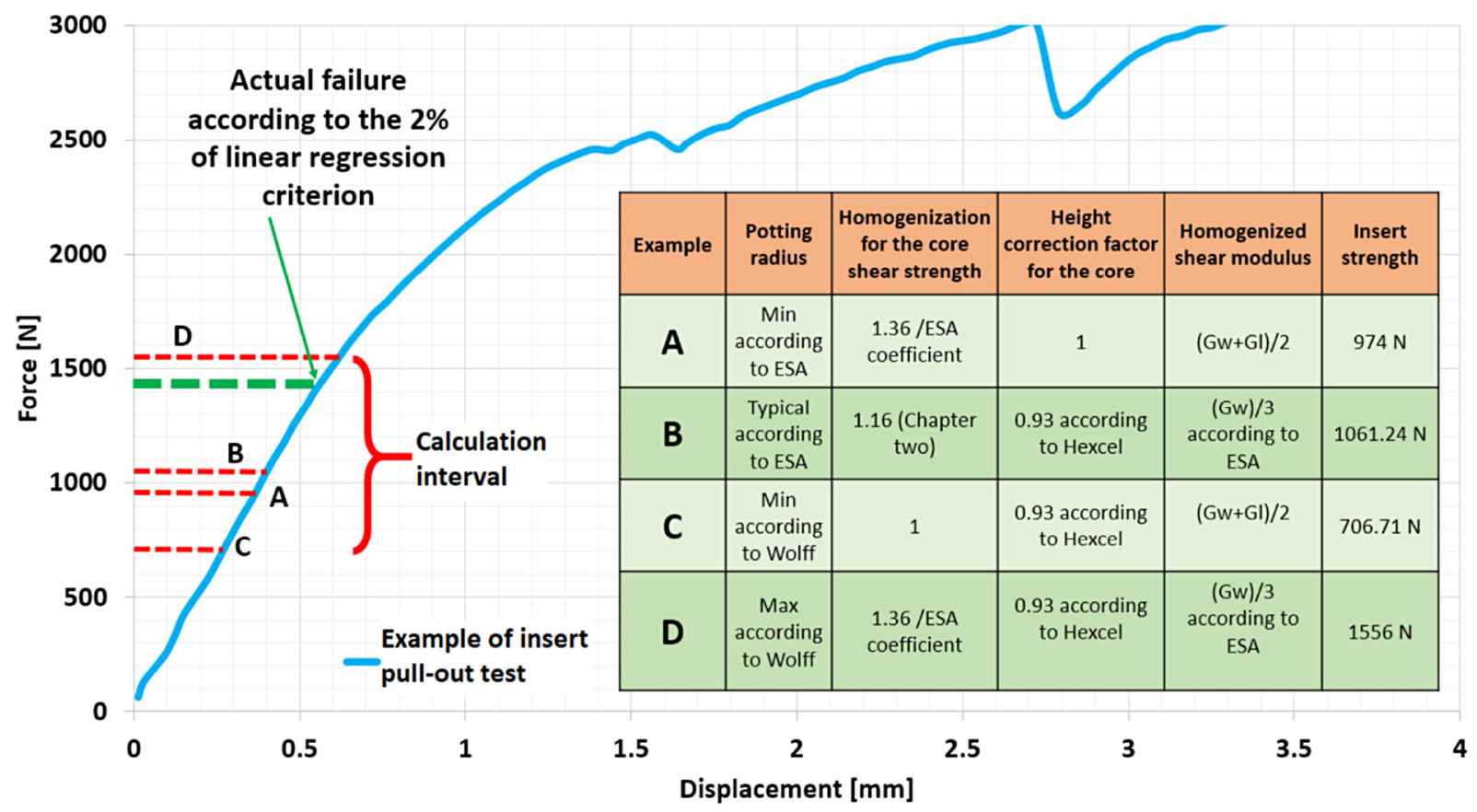

Fig. 3. Example of the calculation of an insert strength using different coefficients. 
calculation time. Then, this model is parametrized by means of Abaqus and Python scripting in order to be used intensively to draw an example of a failure mode map for inserts.

\section{Development of the insert numerical model for virtual testing}

This section presents the main aspects of the numerical modeling of insert pull-out tests. It is well known that numerical models are often used for the design of structures. They give a consistent estimation of the strains and stresses, which is very useful for the embodiment design stage. These models are known to reliably predict the linear behavior of structures. However, when nonlinear considerations are included, such as contact, buckling or material degradations, their predictions cannot be accurate unless great care is taken when introducing such aspects. For this reason, the numerical analysis using nonlinear models must be always validated through experimental tests. The role of the experiment is to allow key information be collected that can be used as guide for the development of the nonlinear model. In this sense, once the numerical model is capable of reproducing the nonlinear behavior of the structure, its role is to provide insight into the analysis of stresses and deformations that cannot be measured experimentally. This numerical-experimental dialogue is very helpful to better understand how and why structures fail. For this reason, the development of the insert numerical model that follows is divided into several steps. First, several pull-out tests are performed to gather the experimental evidence needed. Then, the development of the numerical model of the insert is presented to correlate with the experimental linear behavior of the experiments.

\subsection{Gathering the experimental evidence: insert pull-out testing}

Seven insert pull-out tests were performed to gather the experimental evidence needed for the numerical model. The specimens corresponded to the specifications of sandwich panels used for helicopter interiors. The material properties are shown in Table 1. The skins are made of two layers of G939/145, the core is in Nomex honeycomb, and the insert is potted with Araldite AV121B mixed with $10 \%$ of its weight of phenolic microspheres with an average diameter of $90 \mu \mathrm{m}$. These specimens were left over from a series manufactured for the research presented in [21]. All of them were made using the material and geometry specifications shown in Fig. 4. First, a hole $17.32 \mathrm{~mm}$ in diameter was made in the panel and an undercut was performed to increase the diameter of the insert potted section to $33 \mathrm{~mm}$. Finally, the metal insert was placed, and the potting was injected. The specimens were left to cure at room temperature for several days.

\subsubsection{Test setup}

To perform the tests, a test fixture was used as recommended by ESA in [10]. The center hole had a diameter of $60 \mathrm{~mm}$ and a $10 \mathrm{kN}$ Instron machine was employed. The displacement was imposed at a constant speed of $0.5 \mathrm{~mm} / \mathrm{min}$. The applied force was measured directly from the machine while a 3D digital image correlation system was used for the displacement. This setup measured the actual pull-out displacement applied to the insert, which was defined as the difference between the metal insert displacement and the skin touching the borders of the test fixture as shown in Fig. 5. Two LDVT sensors were used to measure the imposed displacement but the data obtained were not coherent.

\subsubsection{Test results and analysis}

The test curves are shown in Fig. 6b. The average linear stiffness of the specimens was $6750 \mathrm{~N} / \mathrm{mm}$, and the average failure load according to the $5 \%$ failure criterion was $1091 \mathrm{~N}$, while the maximum and minimum failure loads were $1281 \mathrm{~N}$ and $857 \mathrm{~N}$ respectively. These failure loads were calculated by inspecting the stiffness of the tested specimens (omitting the initial contact effects) and then searching for a change equal to or greater than $5 \%$ in the stiffness (see Fig. 6a). A MATLAB script was developed to avoid detections of local changes

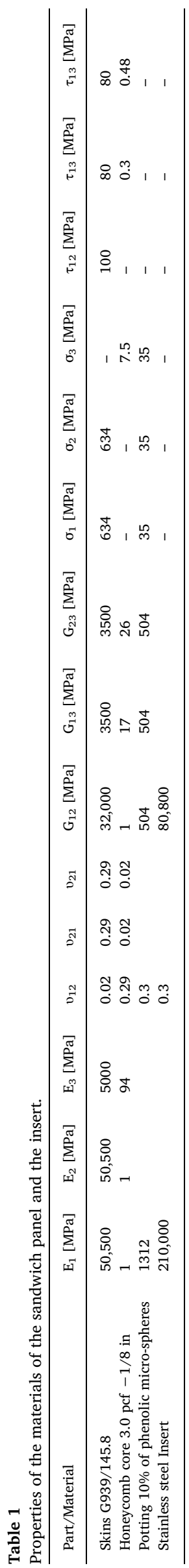




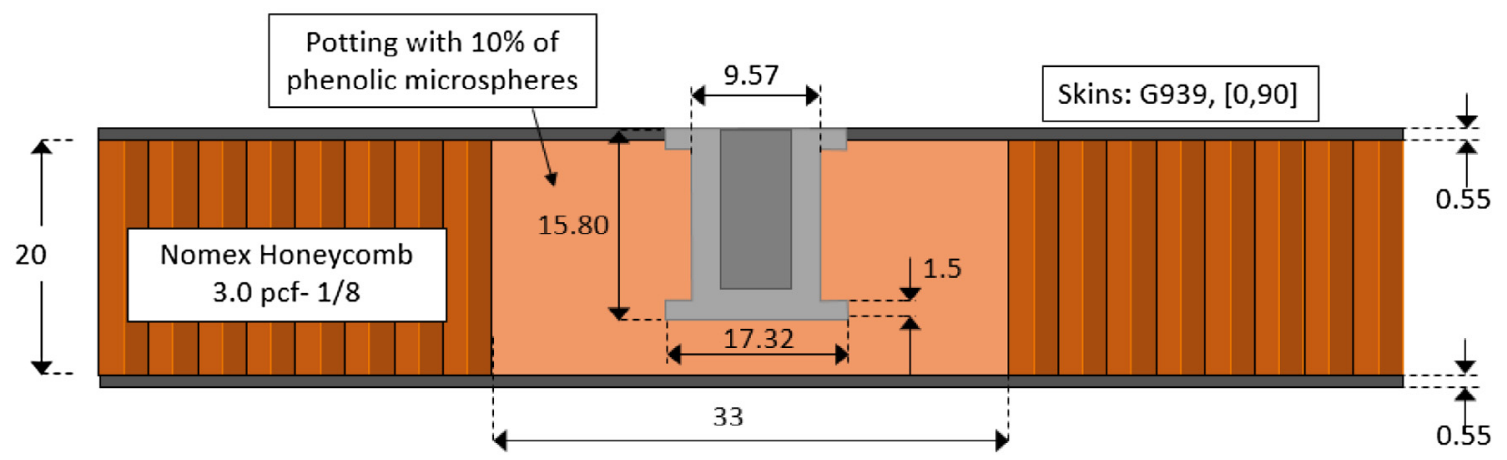

Fig. 4. General description of the insert specimens tested.

(fake failures) due to noise in the force and displacement signals. During the test, the detaching of the metal insert from the skins (see Fig. 7) could be observed with the naked eye. For EP1, this started to be noticeable at $0.96 \mathrm{~mm}$ of displacement.

Then, the tested specimens were cut in half to be inspected. Several remarks can be made. The potting diameter was supposed to be $33 \mathrm{~mm}$ but, in the specimens, it varied from $30 \mathrm{~mm}$ to $39 \mathrm{~mm}$ - as expected due to the discrete nature of the honeycomb cells. At first sight, all the fasteners were well bonded since none of them became detached from the potting. Also, the breaking of the potting surrounding the insert (as the images shown in Fig. 7 may suggest) only appeared for two specimens (EP5 and EP7) and not for the others. This may have been because the small fractures or gaps closed when the pull-out load was removed. As expected for inserts installed by hand, there were many air bubbles and the borders of the potting were very irregular. Several failure modes can be identified: core shear failure (buckling and collapse of the cells), tensile breaking of the core, fracture of the potting, and breaking of the potting/skin interface (see Fig. 8).
The folding of the honeycomb cells appeared to start from the upper three-material contact point (potting, skin, honeycomb) for both double or single walls as can be seen in the sections of EP1, EP3, EP5 or EP6 shown in Fig. 8. This seems contradictory to the concept of effective potting radius explained by ESA in [10], which states that the double walls next to the potting do not fold and, thus, the failure should appear only in the nearest single walls. Concerning the estimation of the pullout strength using the ESA approach, with an effective potting radius of $19.04 \mathrm{~mm}$, using a factor of 1.36 for the correction of the core shear strength as suggested in [10] (which results in an admissible shear of $0.41 \mathrm{MPa}$ for the honeycomb core) and a homogenized shear modulus of the core of 21.5 MPa, the failure load should be around $1363 \mathrm{~N}$. This estimation is out of the range of the maximum and minimum strengths measured experimentally (see red dashed lines in Fig. 6b) and overestimates the average failure load (detected by the $5 \%$ dev. criterion) by $24 \%$ (see dashed blue line in Fig. 6b).

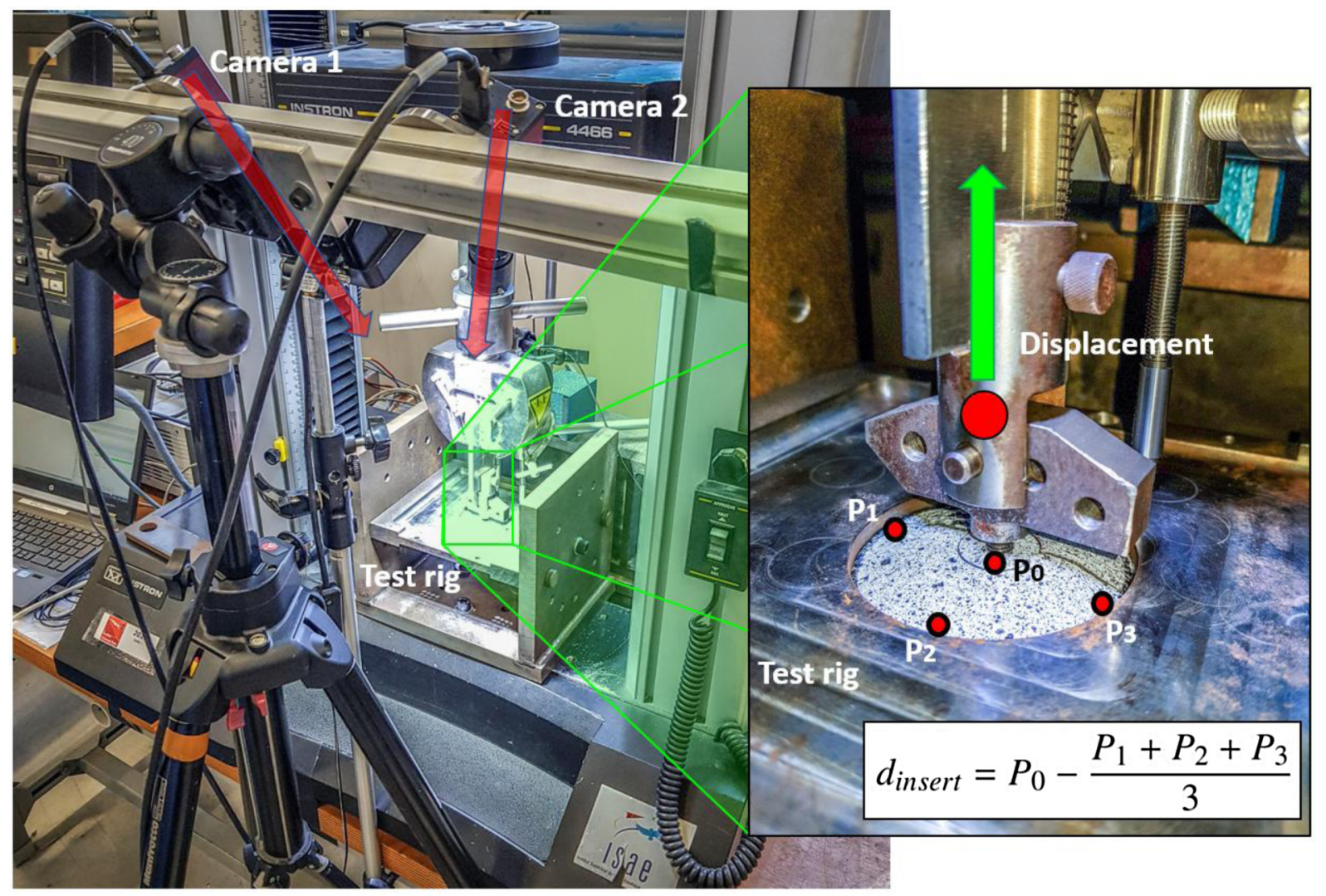

Fig. 5. Set up for the pull-out testing of the inserts. 

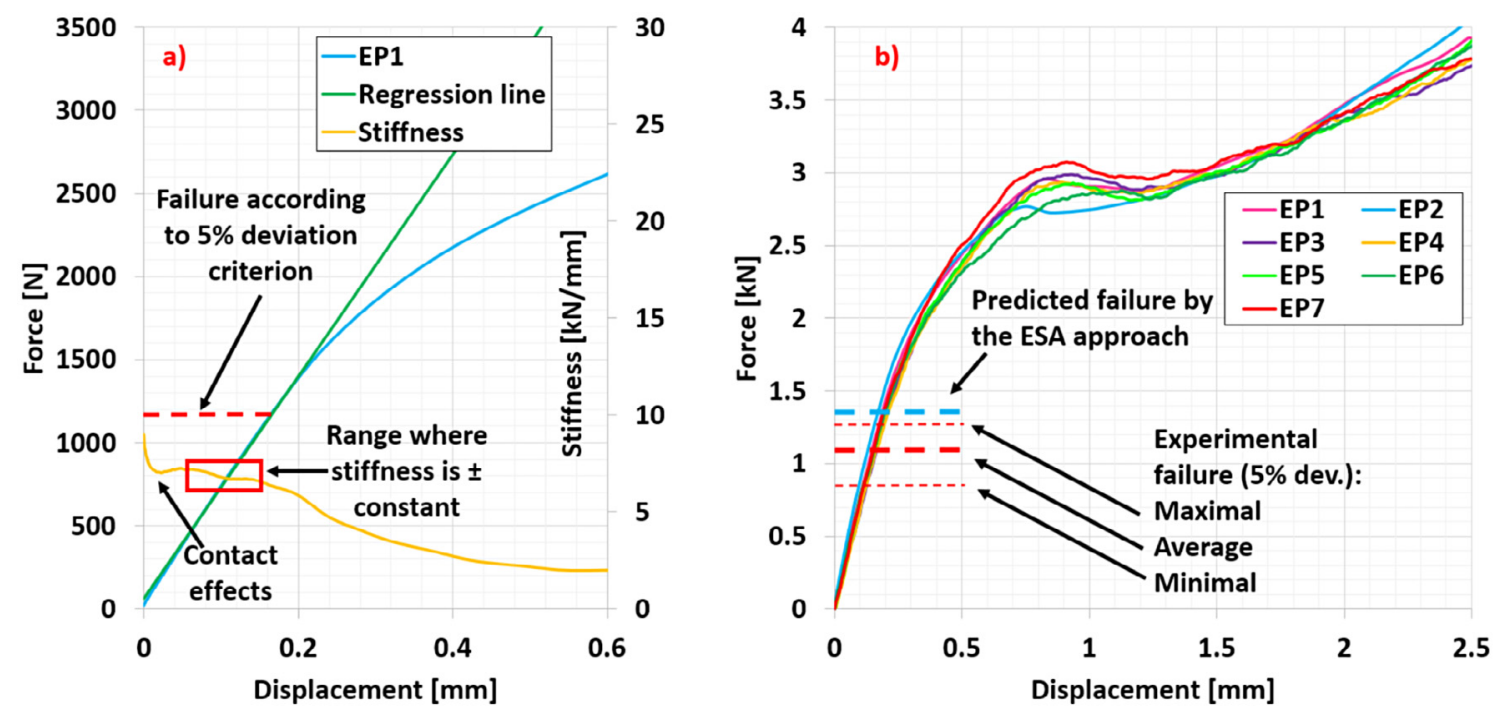

Fig. 6. a) Example of the calculation of the failure load of the inserts according to the 5\% deviation criterion, b) Experimental curves of the pull-out tests.
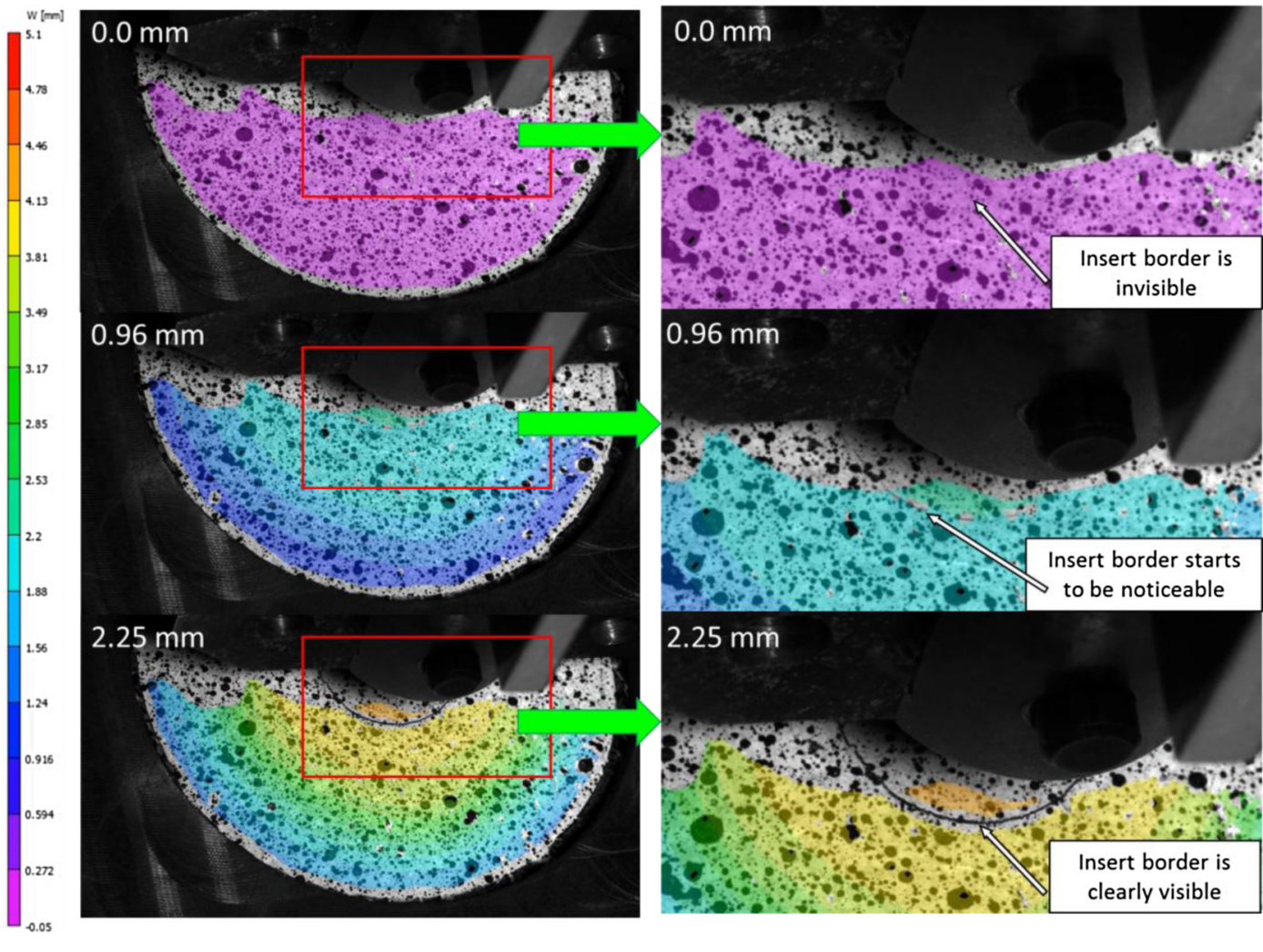

Fig. 7. Progressive detachment of the metal insert from the sandwich panel.

\subsection{Numerical modeling of the insert}

In this sense, the pull-out tests are intended to be reproduced numerically. To do this, the properties and geometry given in Table 1 and Fig. 4 are considered and, since the testing speed was very low, the insert was modeled using Abaqus implicit. In contrast to the very detailed models of Seemann [29], Roy [20] or Slimane [32], the numerical model of this research is kept as simple as possible to reduce the calculation time, bearing in mind that the accuracy should not be compromised too much. For this reason, whenever possible, the geometry of the specimens is simplified to facilitate its parameterization and a homogenized continuum $3 \mathrm{D}$ approach is used to represent the materials. The potting geometry is drawn as a regular cylinder of radius $18.43 \mathrm{~mm}$ regardless of the irregular shape it typically has due to the discrete nature of the honeycomb cells (see Fig. 7). This simplification is based on the Real Potting Radius (RPR) also proposed by ESA in [10], which is congruent with the evidence of Fig. 8, where both single and double walls fold without distinction. It is important not to confuse the Real Potting Radius and the Effective Potting Radius (EPR). The first is calculated considering an equivalent potted circular surface, while the EPR is calculated considering that only the single walls fail. For clarity, this distinction is illustrated in Fig. 9.

Also, the fastener geometry was simplified as shown in Fig. 10-a. The original contact surface areas between the metallic insert and the 


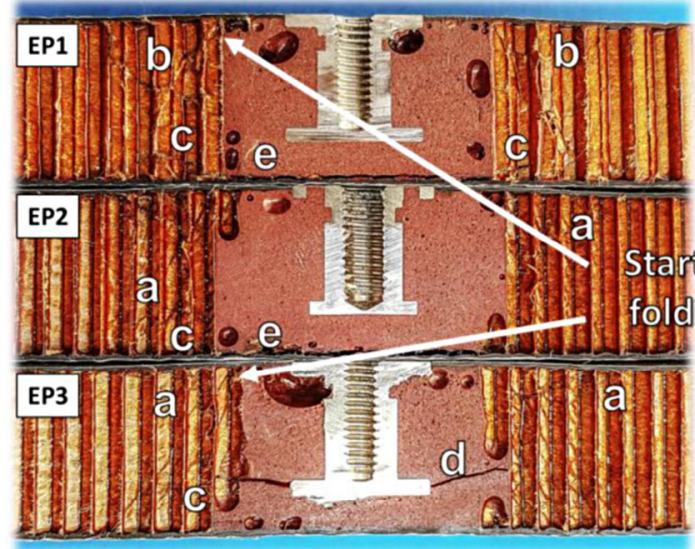

a) Shear buckling of the cells

b) Shear folding of the cells

c) Tensile rupture of the core

d) Breaking of the potting

e) Breaking of the potting/skin interface
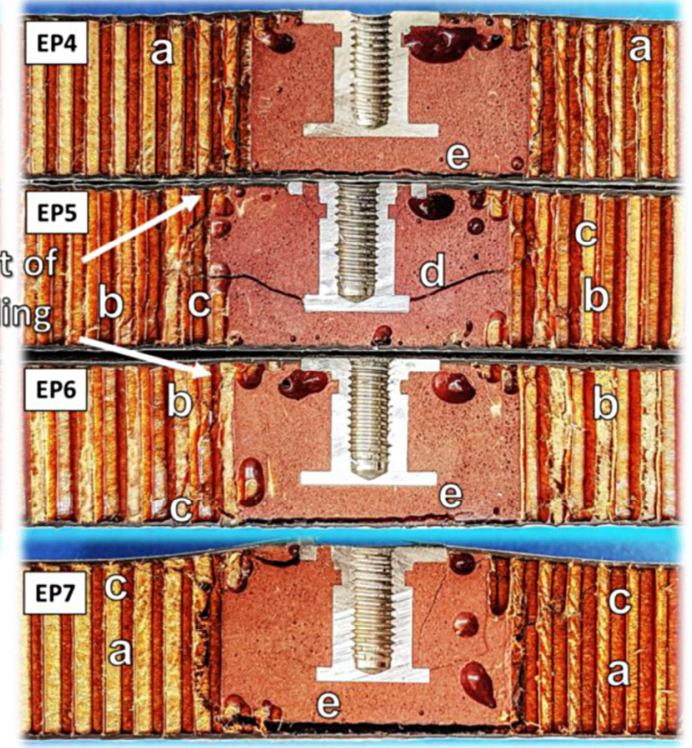

Fig. 8. Identification of the failure modes of the tested specimens.

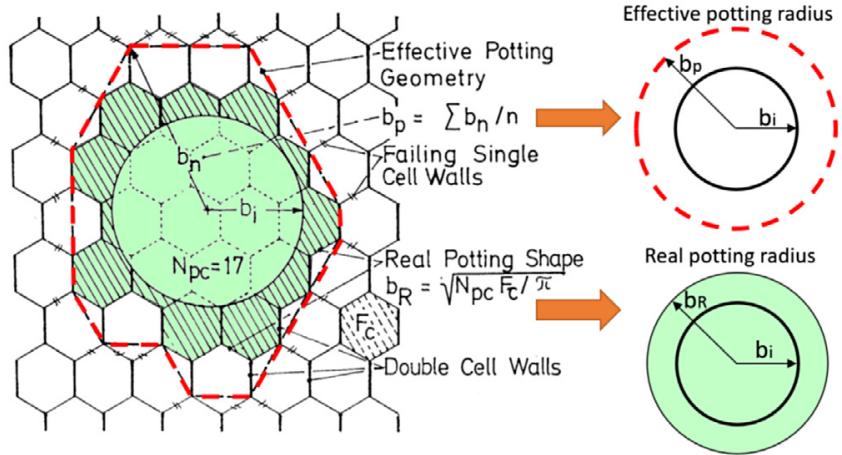

Fig. 9. Real potting radius (green surface) vs Effective potting radius (red dashed line), reproduced from [10].

potting were replaced by a simplified equivalent surface. As explained in [27], the honeycomb cells that surround the insert might have different shear behaviors. Briefly, this is because the potting creates a lateral stabilization effect that alters the shear behavior of the surrounding cells. For this reason, the core is divided into two sections: one near the insert (Fig. 10b in blue) with a radius of two cells beyond the potting, and the other the rest of the honeycomb (in red). As for the types of elements, only brick elements are used to represent the materials, including the skins, the honeycomb core, the potting and the fastener. For the core, this allowed the CDM approach presented in [33] to be implemented, providing a good alternative to include the shear nonlinear behavior of the core at low computational cost.

\subsubsection{Material laws}

The elastic material properties given in Table 1 are considered. However, to detect the insert pull-out strength, material failures are included in the numerical model through behavior laws (UMAT for Abaqus standard) for the CFRP skins, the potting, and the Nomex honeycomb core (see Fig. 11). For the skins, the in-plane and transversal matrix failure are included at $100 \mathrm{MPa}$ and $80 \mathrm{MPa}$ respectively. After these limits, the stiffnesses in the respective directions are reduced by $85 \%$ to avoid numerical instabilities and they are not coupled (see Fig. 11a). This value is sufficient, since the objective is to follow only the beginning of the nonlinear behavior here. The behavior of the potting under tension includes a Young modulus of $1660 \mathrm{MPa}$ and brittle fracture at 14.5 MPa. After this limit, the stiffness is reduced by $99 \%$ to simulate a brittle failure. On the other hand, under compression, the Young modulus of the material is $1226 \mathrm{MPa}$ and the behavior law includes an isotropic perfect plasticity model starting at $26 \mathrm{MPa}$. The
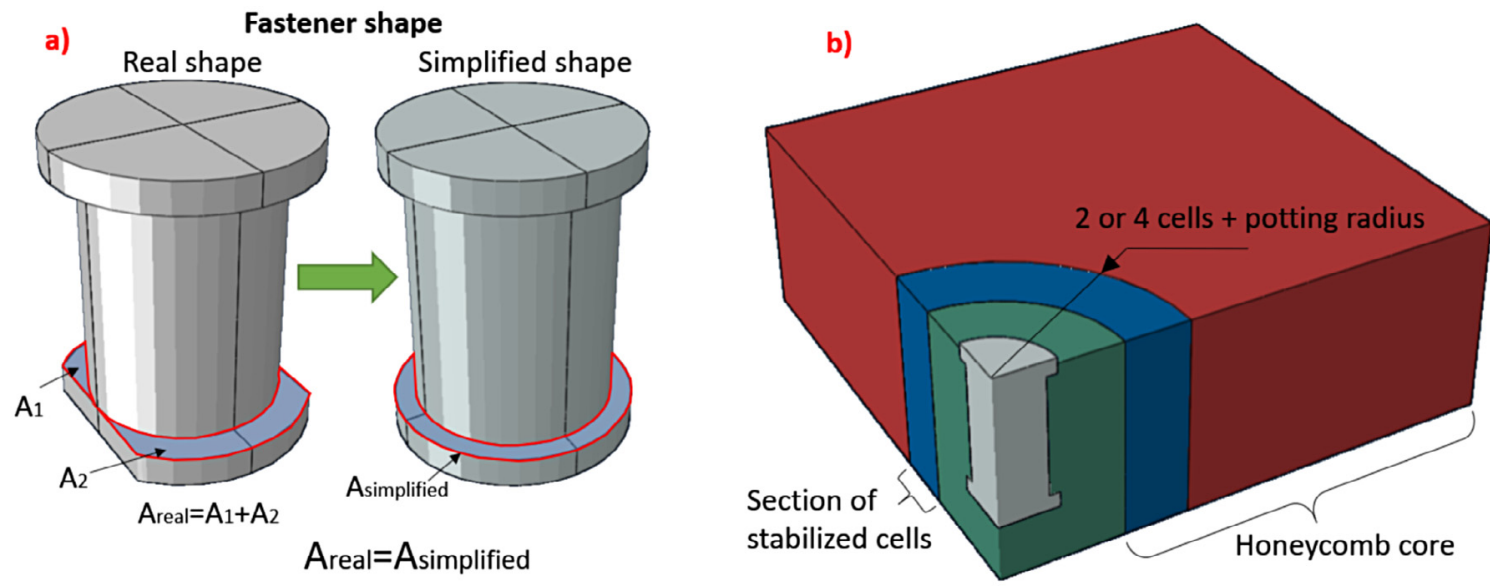

Fig. 10. a) The core near the insert is considered as a different section because its behavior is different; b) the fastener geometry is simplified. 
a)

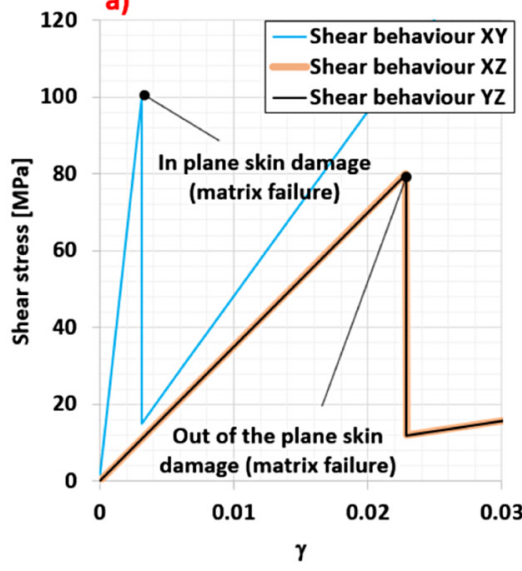

b)

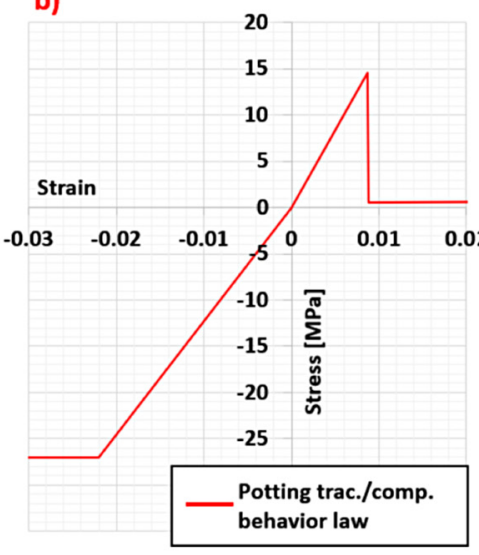

c)

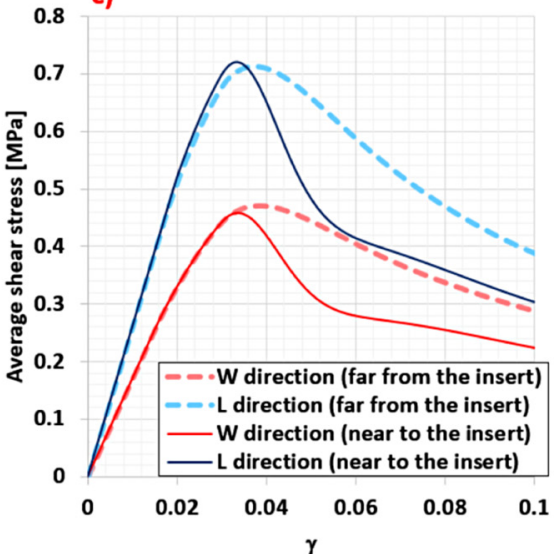

Fig. 11. a) Shear behavior laws of the skins, b) traction-compression behavior laws of the potting and c) shear behavior laws of the honeycomb core.

Table 2

Parameters used for the behavior laws of the honeycomb core in the CDM approach presented in [33].

\begin{tabular}{clllll}
\hline & & $\begin{array}{l}\text { W dir. } \\
\text { (near the } \\
\text { insert) }\end{array}$ & $\begin{array}{l}\text { L dir. (near } \\
\text { the insert) }\end{array}$ & $\begin{array}{l}\text { W dir. (far } \\
\text { from the } \\
\text { insert) }\end{array}$ & $\begin{array}{l}\text { L dir. (far } \\
\text { om the } \\
\text { insert) }\end{array}$ \\
\hline Initial buckling & $\mathrm{A}_{\mathrm{b}}$ & 0.9 & 0.9 & 0.9 & 0.9 \\
stage & $\lambda_{b}$ & 0.057 & 0.05 & 0.057 & 0.05 \\
& $\gamma_{\mathrm{b} 0}$ & 0.015 & 0.19 & 0.015 & 0.19 \\
Collapse stage & $k_{b}$ & 1.35 & 1.35 & 1.35 & 1.35 \\
& $\mathrm{~A}_{\mathrm{c}}$ & 0.5 & 0.5 & 0.36 & 0.34 \\
& $\lambda_{c}$ & 0.015 & 0.015 & 0.025 & 0.025 \\
& $\gamma_{\mathrm{c} 0}$ & 0.03 & 0.018 & 0.03 & 0.03 \\
& $k_{c}$ & 2 & 2 & 1.5 & 1.5 \\
\hline
\end{tabular}

shear failure of the potting material is not included (see Fig. 11-b). Finally, for the Nomex honeycomb core, the CDM approach presented in [33] is implemented. This method uses two different variables to consider, first, the effect of the elastic reversible buckling of the cells and, second, the permanent damage of the collapsing cells. This approach is used to simulate the shear nonlinear behavior of the cells near and far from the insert. The coefficients of Table 2 refer to the approach presented in [33]. The nonlinear behavior of cells starts at $\gamma_{\mathrm{b} 0}$ and they collapse at $\gamma_{\mathrm{c} 0}$. The resulting behavior laws are shown in Fig. 11c.

\subsubsection{Meshing and boundary conditions}

For the meshing, the skins are composed of two layers and therefore they have two elements of thickness each. The core is meshed with only one element as explained in [33] and, for the rest of the parts, the size can vary according to the accuracy desired. Symmetry is considered and only one quarter of the specimen is modeled. Also, the $\mathrm{Z}$ displacement of the upper skin nodes at a radius of $30 \mathrm{~mm}$ is restricted to include the effect of the testing support (see Fig. 5). The displacement is imposed at the center of the fastener as shown in Fig. 12

\subsubsection{Validation of the numerical model: real test $v s$ numerical testing}

The numerical simulation was performed using 8 processors and $8 \mathrm{~GB}$ of RAM. The calculation took $7 \mathrm{~min}$. The numerical curves showed good correlation with the experimental results up to a displacement of $0.85 \mathrm{~mm}$. The core shear failure was well represented, and the cells were seen to start to collapse a few millimeters away from the potting (see Fig. 13-a) as the analytical approach in [10] suggests. Breaking of the potting appeared in the upper borders surrounding the insert (see Fig. 13) after $0.9 \mathrm{~mm}$ of imposed displacement, which is consistent with the experimental evidence shown in Fig. 7. As for the skin matrix failure, the numerical model suggests it appears before the potting

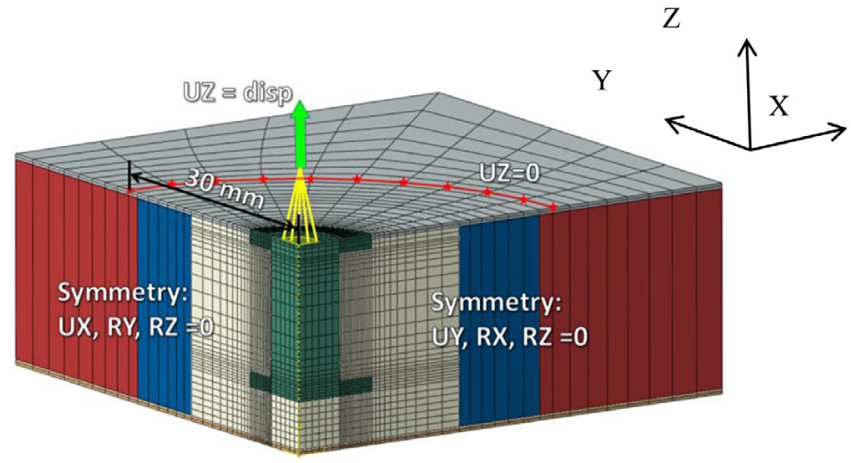

Fig. 12. Boundary conditions and meshing of the simplified numerical model.

breaks but, unfortunately it was not possible to verify this experimentally.

The lower potting/skin interface does not appear since the breaking of the potting/ skin interface was not included in the model. This could explain the difference of the numerical and experimental curves after $0.85 \mathrm{~mm}$ of displacement. Also, the breaking of the potting beneath the insert that appeared in specimens EP3 and EP5 (letter d in Fig. 8) does not show up. Both of the last failures modes may be related to the inclusion of defects; the lower skins were not properly degreased and cleaned before the injection of the potting so the interface might have been very weak and easy to break. As far as the breaking of the potting is concerned, it could be explained by a higher local concentration of phenolic microspheres or an inefficient degreasing of the bottom of the metal insert, which would have weakened the potting or the pottinginsert interface in the zone where the fracture appears in the real tests. It is also worth mentioning that the numerical model predicts a maximum stress of about $9 \mathrm{MPa}$ beneath the insert, which is lower than the tensile elastic limit of the behavior law, of 14.5 MPa.

2.2.4. Conclusions on the numerical approach for virtual testing of inserts Setting aside the problems mentioned above, this simplified numerical approach can detect the activation of three failure modes: first the shear collapse of the cell walls of the core at $0.34 \mathrm{~mm}$ of displacement, followed by the in-plane matrix failure of the skins at $0.7 \mathrm{~mm}$ of displacement, and then the potting breaking in the upper borders next to the metal insert. The fact that the core shear failure appears before any other failure is consistent with the typical failure of most inserts, as ESA states in [10]. Nevertheless, the numerical model predicts core shear failure at $1750 \mathrm{~N}$ while the analytical approach of ESA estimates the failure at $1363 \mathrm{~N}$ and, experimentally, according to the $5 \%$ dev. criterion, the failure load is $1091 \mathrm{~N}$. 


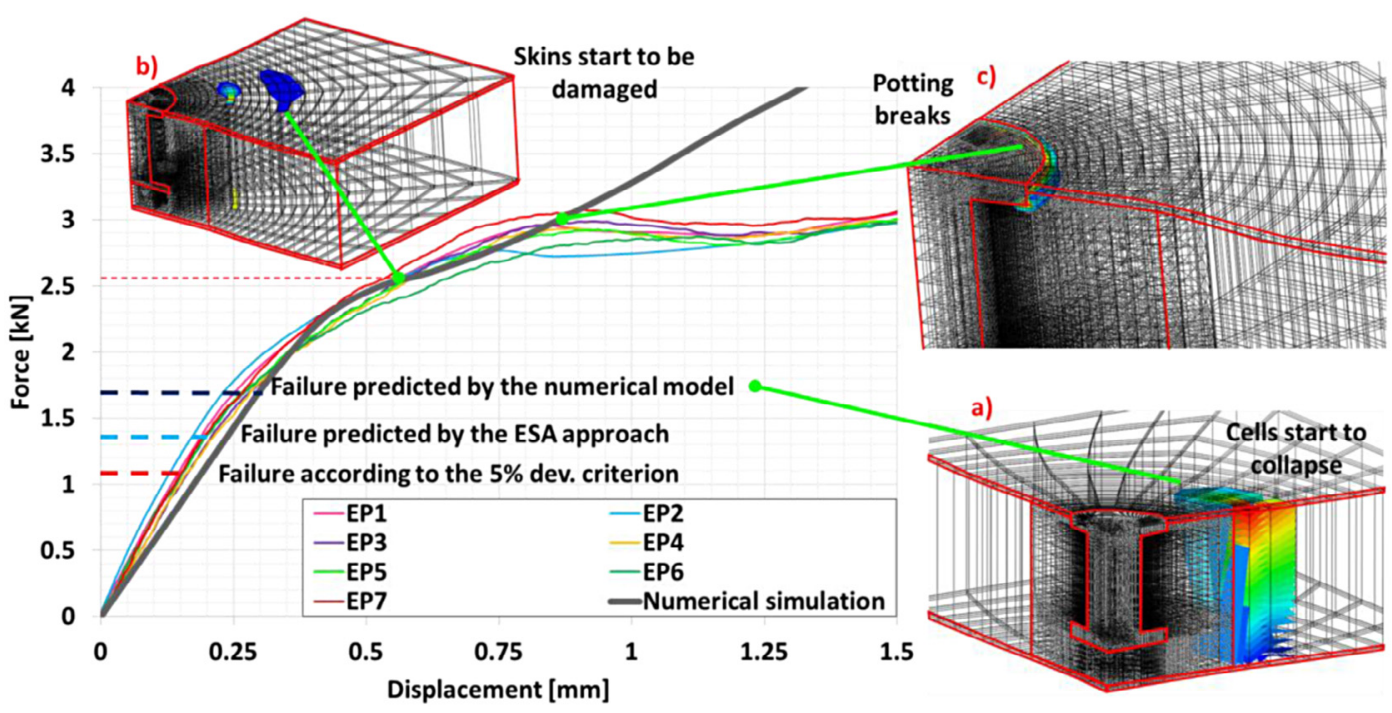

Fig. 13. Numerical vs experimental tests: curves and failure modes.

It should not be forgotten that the $5 \%$ dev criterion is not based on the integrity of the sandwich and insert materials but on the overall insert behavior, and this could be very penalizing for sandwich panel inserts with a Nomex honeycomb core. The research presented in [27], where it is shown that Nomex honeycomb core exhibits reversible elastic buckling under shear loads and, more importantly, that most of the shear behavior happens to be in this nonlinear elastic behavior zone, suggests that using a criterion based on the linear behavior (such as the $5 \%$ dev. criterion) penalizes and underestimates the actual strength of the insert. Even so, this criterion is largely used for insert testing as it is practical and estimates the failure load with a certain safety margin (see for example [20,26]). For these cases, it could be more profitable to identify the true shear stress at which the core starts to be damaged (or the point where the cells start to collapse) and to implement this limit in a numerical model, as was done for this research (except that the admissible shear stress used here was assumed and not identified experimentally).

In conclusion, the simplified numerical modeling presented in this research has several advantages. It allows the most common failure modes, such as core, potting and skin matrix failure, to be detected. It also allows the nonlinear elastic behavior of the honeycomb core to be taken into consideration (which cannot be done analytically) and, thanks to the CDM approach used for the honeycomb core [33], the simulation time was about $7 \mathrm{~min}$, which is very important since a parametric study is foreseen. Also, this numerical model is useful to understand how the insert fails and the order in which the materials do so. When the pullout load is applied, the core is subjected to shear stress. Then, the first change of slope in the insert behavior is caused by the buckling of the honeycomb core, which reaches a bifurcation point. Then, matrix failure is detected. The potting apparently breaks in the upper borders touching the metal insert. It should be noted that, as far as the potting breaking prediction is concerned, this is only a rough analysis since the failure of syntactic polymer foams is much more complex. A more detailed study, possibly including fatigue, could result in the prediction of the potting breaking even earlier than the core shear failure, which could help to explain the issues related to the water sealing joints of sandwich panels presented by Shafizadeh et al. in [5].

\section{Plotting the insert failure mode map}

\subsection{Introduction}

Failure mode maps describe the different failure modes of a structure in terms of its intrinsic properties like dimensions, materials, boundary conditions, etc. An example of this was presented by Triantafillou et al. in [34] or by Petras et al. in [35], where the different failures of the sandwich structure are represented using a map. Petras compiled the formulas used to calculate the various strengths of the failure modes of sandwich panels under certain conditions, like face yielding, face wrinkling, and core shear failure, among others. Then, all these expressions were evaluated to determine which failure mode was activated first. At the end, they obtained a chart where the failure modes could be easily identified according to the properties of the sandwich. This same approach has been proposed by other authors like Vitale et al. [36] to tackle complex problems for the description of the failure of natural and synthetic fiber reinforced composite sandwich panels, or Andrews et al. [37] to represent the failure modes of composite sandwich panels subjected to air blast loading.

The creation of failure mode maps enables the transition limits of different failure modes to be detected, which are of special interest for mass reduction problems because they point out the structural parameters that present the best compromise between strength and mass. This is interesting for aeronautical structures but such optimization might be difficult for complex structures that rely on several parameters. This is the case of inserts for sandwich panels. As quick example, let us consider that, if the core is always the first component to fail, at first sight there is no sense in using a stronger potting adhesive or a metallic insert that might add unnecessary weight to the panel; a lighter insert and potting could help to save a few kilograms, given the total number of inserts in a structure. For this reason, a failure mode map of inserts could help to reduce the weight of structures Nevertheless, there are many different types of sandwich configurations and choices are made according to needs. For this reason, it could be very complex to create a general failure mode map of inserts since their strength relies on the several dimensions and the materials that can be used.

It is important to emphasize that this research only proposes a path that could be followed to draw an insert failure mode map, which should be used only for the design of similar types of inserts, e.g., in the case studied here, fully potted inserts for aeronautical sandwiches with thin CFRP skins and a $20 \mathrm{~mm}$ thick Nomex honeycomb core. Also, this failure mode map does not consider the influence of defects and the mechanical properties of the potting used for the parametrical study are not the same as those used for the numerical model in the previous section. This is because, in the literature (see Table 5 in annex) most inserts are potted with pure adhesive and not with syntactic polymer 
foam like the specimens presented in the previous section. Therefore, the failure mode map that will be presented is only provided for demonstration purposes.

\subsection{Parametric study of the insert pull-out strength}

The next step of this research is to use the previously presented, simplified numerical approach to the insert in order to perform a parametric study and plot the insert failure mode maps. To do this, the numerical model was parameterized using Python and Abaqus scripting. Each move made on the CAE environment was recorded using the macro editor. In this way, Abaqus wrote the code necessary to build the numerical model, which could then be modified by the user according to the needs. This was of practical advantage because it was not necessary for the user to have a solid background in Abaqus scripting commands. The size of the sandwich specimen was fixed at $100 \times 100 \mathrm{~mm}$ (actually $50 \mathrm{~mm}$ because only a quarter of the model was simulated) with a core thickness of $20 \mathrm{~mm}$. Also, the support radius was fixed at $30 \mathrm{~mm}$ and the model geometry and mesh size were parameterized accordingly.

Concerning the sandwich panel, the same honeycomb core as used for the specimens presented in last section was considered, with a cell size of $1 / 8 \mathrm{in} ., 20 \mathrm{~mm}$ thickness and a density of $48 \mathrm{~kg} / \mathrm{m}^{3}$. For the skins, the same G0939/145.8 CFRP woven fabric was used. Also, to make the simulations easy to track, the script was modified to perform and arrange the simulations in different directories. In this way, the simulations were numbered, stored and described automatically. For the metal insert, a smaller type was used. Finally, only $1 \mathrm{~mm}$ of displacement was imposed for the virtual tests. There are several parameters that can be chosen to plot failure mode maps. For this research, the authors chose the RPR, the tensile strength of the potting and the skin thickness. The RPR was swept from $9.5 \mathrm{~mm}$ to $23.5 \mathrm{~mm}$ since most of inserts of the literature are in this range (see Table 5). The mechanical properties of the potting varied according to the values shown in Table 4. The number of skin layers was swept from 1 to 4 , which is equivalent to sweeping from $0.275 \mathrm{~mm}$ to $1.1 \mathrm{~mm}$ of thickness. Each layer was stacked following a $\left[0^{\circ}, 90^{\circ}\right]$ orientation with respect to the preceding one.

\subsubsection{Sweep of the real potting radius}

The properties of the materials that were used for the parametric study of the potting radius are shown in Table 3. A total of 23 simulations were performed. The failure loads of each component were identified, and the results are shown in Fig. 14. The first remark is the presence of small variations (like noise) in the curves. This is was caused by the discrete time increments of the simulations, which were set automatically by the software. However, the general trend of the curves is clear.

Note that, between $9.5 \mathrm{~mm}$ and $18.5 \mathrm{~mm}$ of RPR, it is the core shear failure that occurs first. This is coincident with the observations of ESA in $[10]$ and most researchers $[18,25]$ that have performed pull-out tests with inserts in this range of RPR radius.
Then, for the interval between $18.5 \mathrm{~mm}$ and $20.5 \mathrm{~mm}$, the three parts failed almost simultaneously while, for an RPR bigger than $20.5 \mathrm{~mm}$ to $22.5 \mathrm{~mm}$, the potting and skins failed before the core and, finally, when the radius was greater than $22.5 \mathrm{~mm}$, the skins failed before all the other parts. This shows that, for a relatively large RPR, the triple failure scenario is possible. However, in practice, the skin matrix failure can only be detected by looking the specimen skins under the microscope or by thermography, and it might escape the sight of researchers because the other failures are much more visible. Moreover, it can be appreciated that there is almost a linear relation between the insert strength and the RPR real potting radius.

\subsubsection{Sweep of the potting properties}

For this part of the parametric study, the RPR was fixed at $9.5 \mathrm{~mm}$, and the potting properties were swept according to the values shown in Table 4. The initial value corresponded to the actual properties of Araldite AV-121B, the rest of the properties were the interpolation values between the original properties and these properties divided by four. This was done for the elastic modulus, the tensile strength and the compressive strength. A total of 13 simulations were performed and the results are shown in Fig. 15.

It is important to emphasize that, in the results chart of Fig. 15, the potting sweep is only represented by the potting tensile strength because it is the most influential parameter for insert failure. Nevertheless, all the other parameters were swept according to Table 4. According to these results, the insert failure was caused mostly by core shear failure. Therefore, the insert strength remained constant until the potting became weak enough and failed first.

\subsubsection{Sweep of the skin thickness}

As in the previous studies, the insert parameters were fixed, except for the thickness of the skins, which was swept from 1 to 4 layers for a total thickness of $0.275 \mathrm{~mm}, 0.55 \mathrm{~mm}, 0.825 \mathrm{~mm}$, or $1.1 \mathrm{~mm}$. Four simulations were performed, and the results are shown in Fig. 16. Also, it is important to emphasize that the skins had the same number of elements in the thickness as layers, except for one layer where two elements were used. The same mechanical properties of the prepreg were used for all the thicknesses. This might be debatable because, when a prepreg is stacked, the mechanical properties are reduced due to porosities and voids among other defects that can be introduced. However, these effects were neglected to simplify the study.

The results show that there was a failure transition when 3 layers were used for the skins. When the skins were thin, the first failure was core shear failure while, when the skins were thick, the predominant failure was potting failure. This happened because, when the skins are thin, the core can be easily deformed in shear and thus absorb the load, while for thick skins, the skins become stiffer and absorb the shear loads, thus protecting the core.

\subsection{Failure mode map}

The failure mode maps of inserts can be plotted by sweeping two

Table 3

Values used for the parametric study of inserts.

\begin{tabular}{|c|c|c|c|c|c|c|}
\hline \multicolumn{7}{|l|}{ Skins } \\
\hline G0939/145.8 [0/90] & 0.275 to 1.1 & 52,000 & 0.09 & 100 & 80 & 80 \\
\hline Reference & $\mathrm{C}[\mathrm{mm}]$ & G_W [MPa] & G_L [MPa] & t_adm W [MPa] & t_adm L [MPa] & Density [pcf] \\
\hline Nomex ${ }^{\oplus}$ phenolic & 20 & 17 & 26 & 0.26 & 0.45 & 3 \\
\hline \multicolumn{7}{|l|}{ Insert } \\
\hline Reference & Real potting radius $[\mathrm{mm}]$ & $\mathrm{E}[\mathrm{MPa}]$ & $\mathrm{v}$ & St max $[\mathrm{MPa}]$ & Sc max $[\mathrm{MPa}]$ & Support radius $[\mathrm{mm}]$ \\
\hline
\end{tabular}




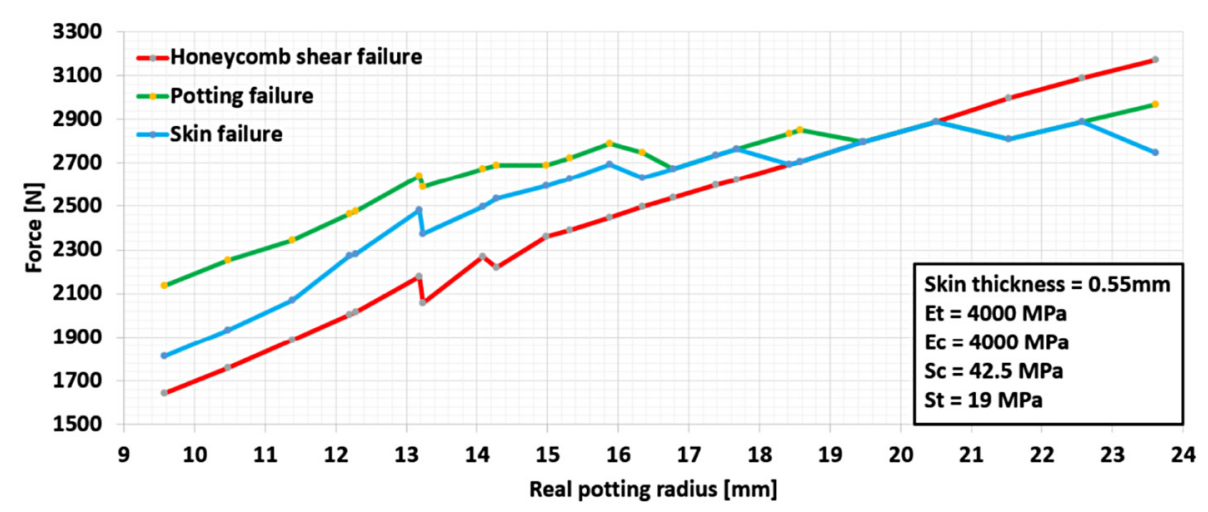

Fig. 14. Failure of the skins, potting and honeycomb core; insert failure load vs Real Potting Radius.

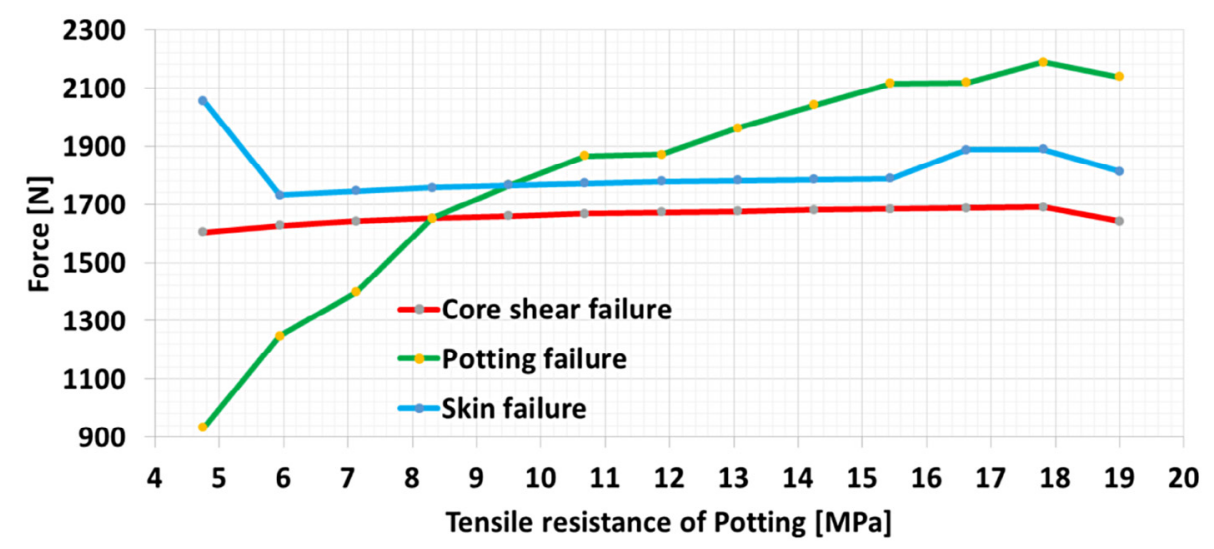

Fig. 15. Failure of the skins, potting and honeycomb core; insert failure load vs tensile resistance of potting.

design parameters at the same time, although, for this research, only one combination is presented in the following section. A total of 60 simulations were run and each calculation took around 5 min to complete. For every simulation the three failure modes were identified, and the load corresponding to each failure mode was used to draw three different surfaces, i.e. each surface was composed of 60 points, as shown in Fig. 17. Although more points could have been obtained, this was considered enough to study the tendency of the failure modes. Insert failure should be produced by the lowest load value of the three failure modes and this is equivalent to viewing the surfaces from the bottom, which is shown in Fig. 18. Notice that, most of the time, it was the core or the potting that failed, and only a small area was composed by the skin failure.

As for the interpretation of the failure mode map; when the insert radius is increased, the potting failure is predominant. This is logical since the contact area between the potting and the fastener remains the same, while the section of the honeycomb core subjected to shear increases (therefore the shear stress concentration decreases). Also, as the tensile resistance of the potting increases, the core shear failure becomes predominant. This occurs because the potting becomes stronger, and can withstand higher loads, while the honeycomb core has the same resistance. When both variables are increased at the same time, there is a transition between the potting failure and the core shear failure, until the applied load is high enough to start to damage the skins before the core and the potting.

Also, in order to show the insert strength as well as the failure modes, a color scale can be used to represent the load range of the insert strength. This is shown in Fig. 19.It can be seen that the insert strength increases as the design parameters do. The color map shows there are different insert configurations that provide similar strength. An example of a criterion for choosing one combination of parameters could be the mass, in which case the configuration with the lowest mass should be used. This type of tool could be very useful for design purposes since it compacts a huge quantity of information into a single 2D chart that can be easily shared among designers.

\section{General conclusions}

The most common analytical approaches provide a rough estimation of the pull-out strength of inserts and their accuracy relies on the correct selection of coefficients for the correction of the parameters. The failure of inserts can also be measured experimentally but the exact failure point is hard to identify since it is not possible to observe the integrity of the components in real time during the test. Moreover, testing is expensive and could take a considerable amount of time. In this context, the virtual testing of inserts proves to be an advantageous

Table 4

Sweeping values for the adhesive based on Araldite AV-121B.

\begin{tabular}{|c|c|c|c|c|c|c|c|c|c|c|c|c|c|}
\hline \multirow[b]{2}{*}{ Tensile Strength [MPa] } & \multirow{2}{*}{$\begin{array}{l}\text { Original properties } \\
19\end{array}$} & \multicolumn{11}{|c|}{ Sweep values } & \multirow{2}{*}{$\begin{array}{l}\text { Properties } / 4 \\
4.8\end{array}$} \\
\hline & & 17.81 & 16.6 & 15.4 & 14.3 & 13.1 & 11.9 & 10.7 & 9.5 & 8.3 & 7.1 & 6.0 & \\
\hline Compression Strength [MPa] & 42.5 & 39.8 & 37.2 & 34.5 & 31.9 & 29.2 & 26.6 & 23.9 & 21.3 & 18.6 & 16.0 & 13.3 & 10.6 \\
\hline Elastic Modulus [MPa] & 4000 & 3750 & 3500 & 3250 & 3000 & 2750 & 2500 & 2250 & 2000 & 1750 & 1500 & 1250 & 1000 \\
\hline Density $\left[\mathrm{kg} / \mathrm{m}^{3}\right]$ & 1400 & 1312.5 & 1225 & 1137.5 & 1050 & 962.5 & 875 & 787.5 & 700 & 612.5 & 525 & 437.5 & 350 \\
\hline
\end{tabular}




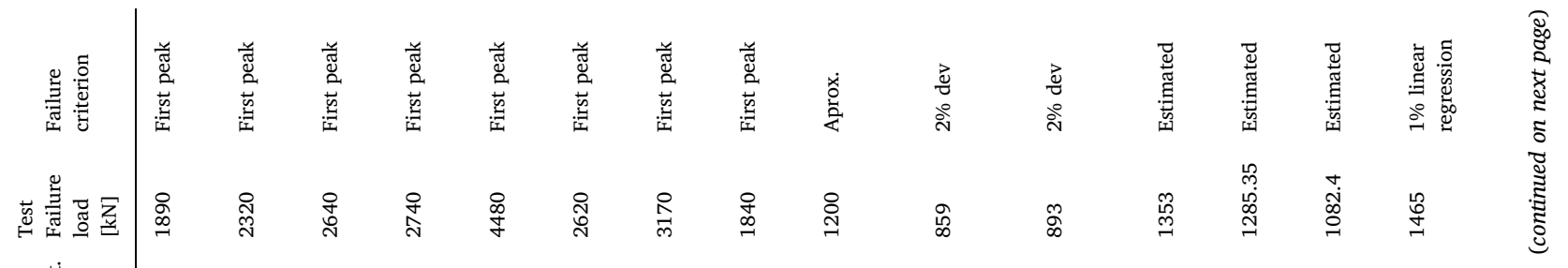

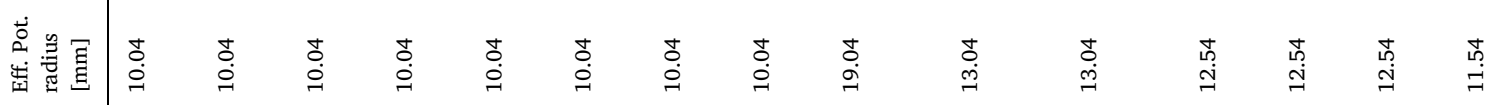

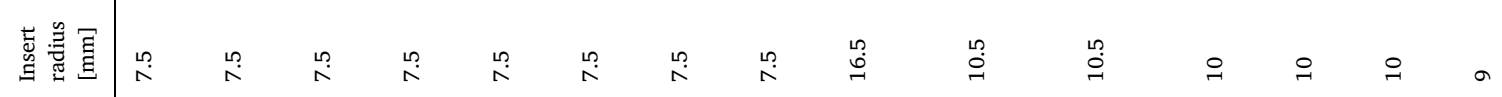

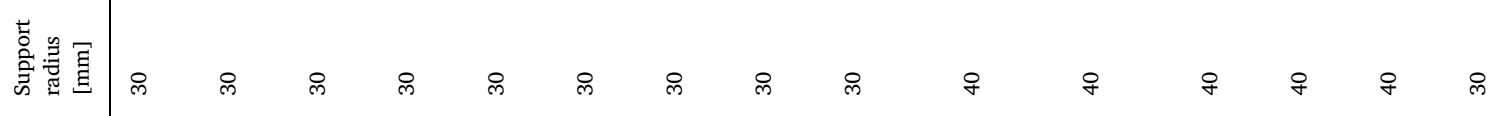

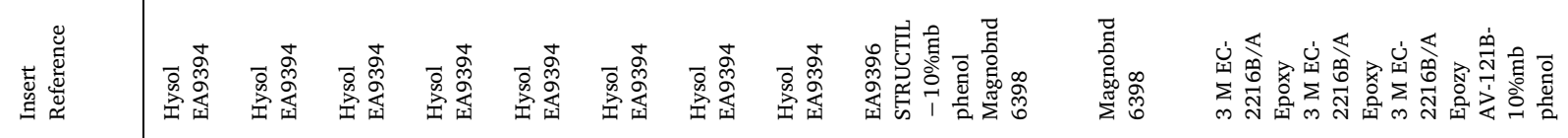

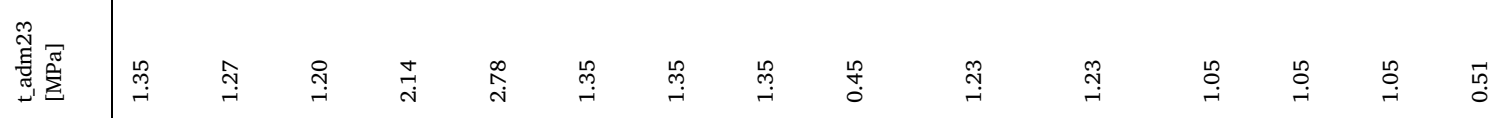

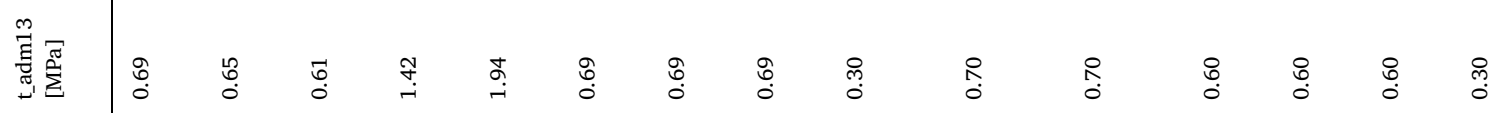

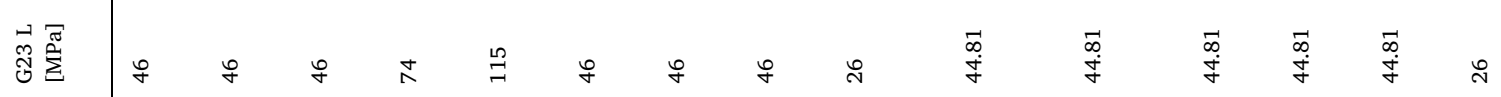

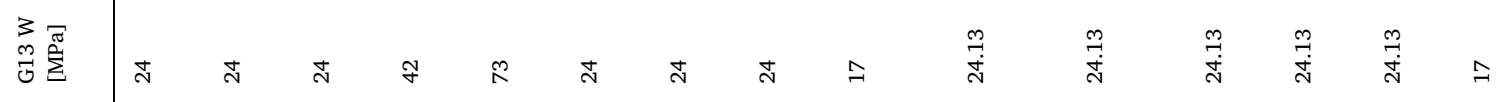

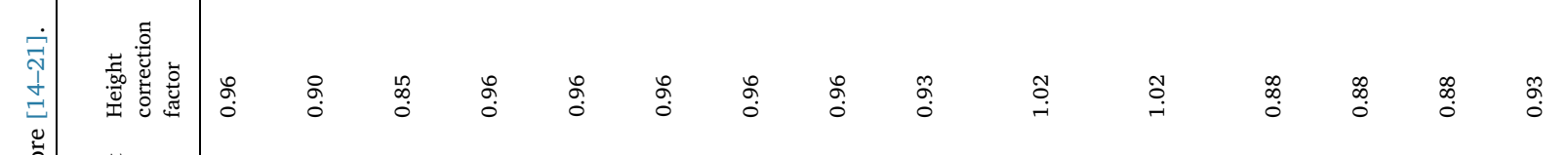

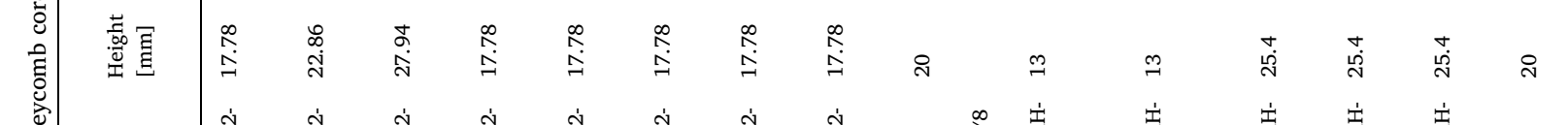

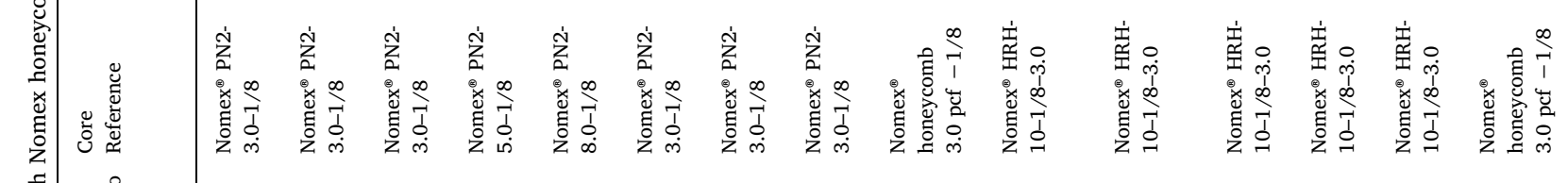
穿

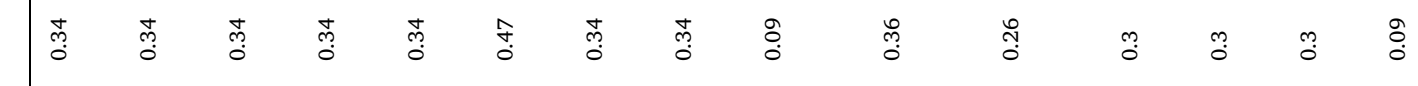

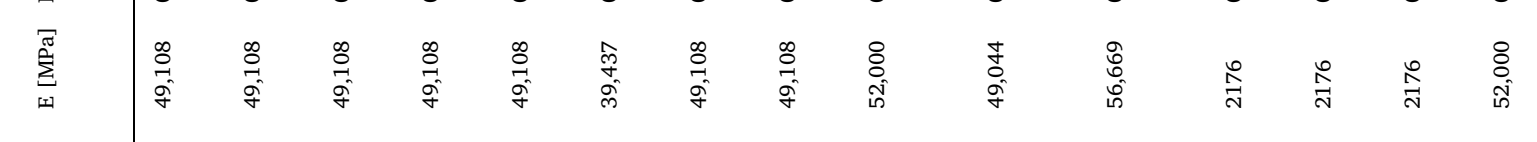

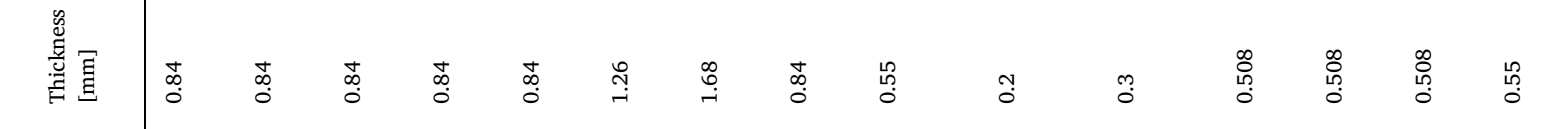

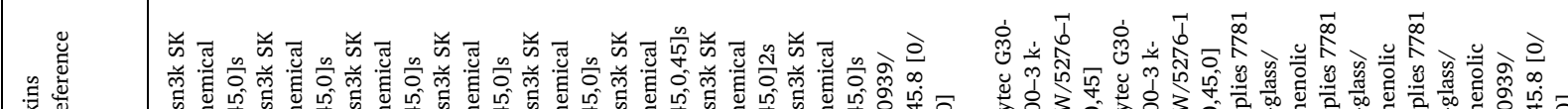

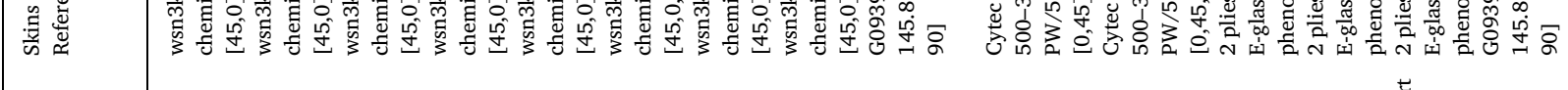

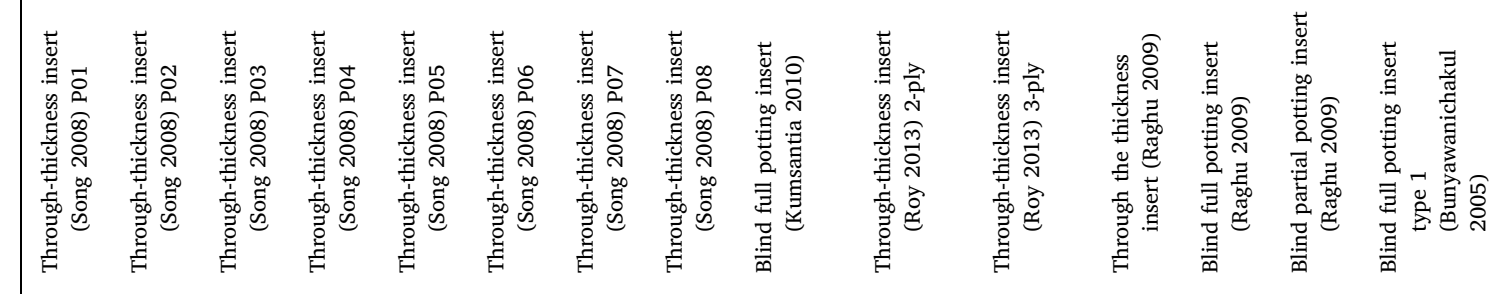




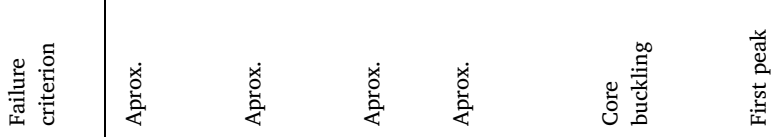

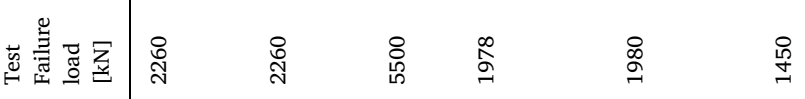

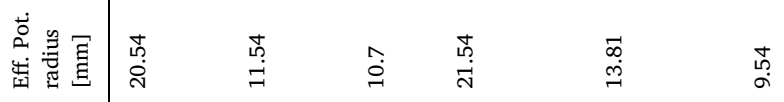

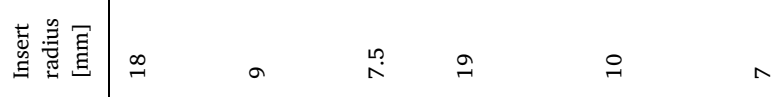

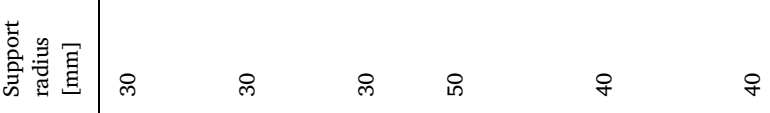

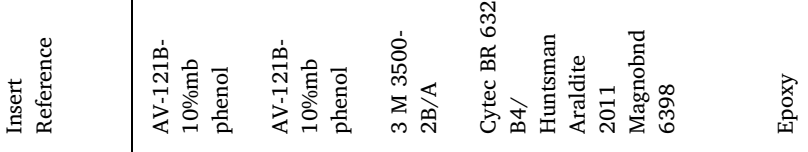

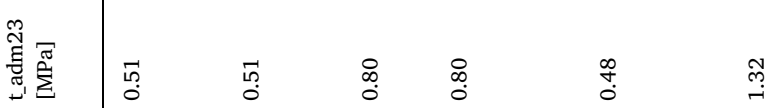

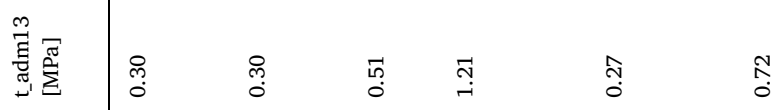

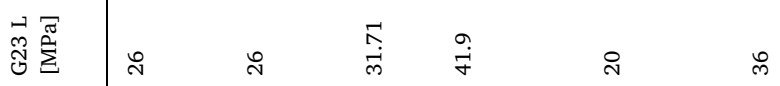
उ西

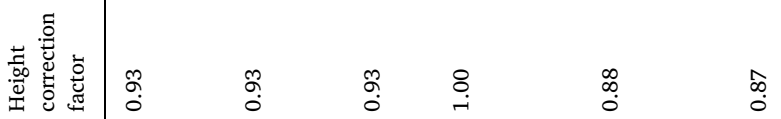

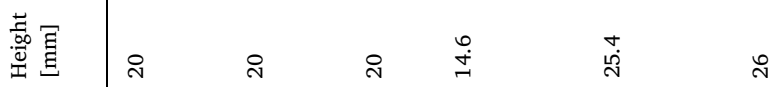

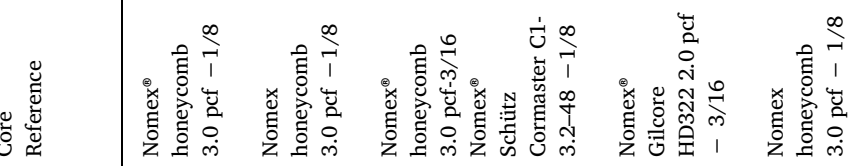

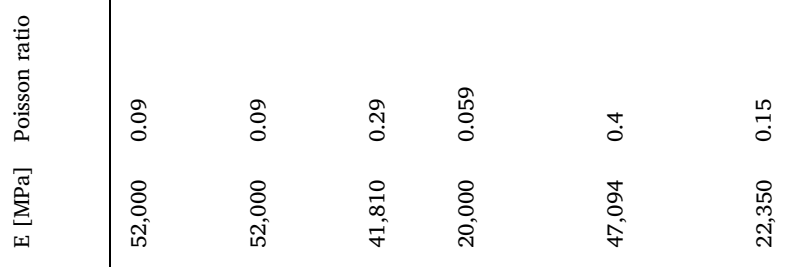

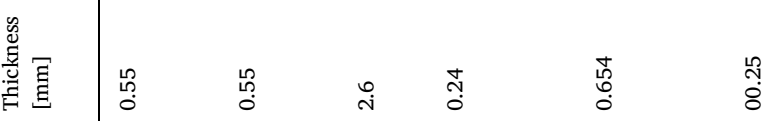

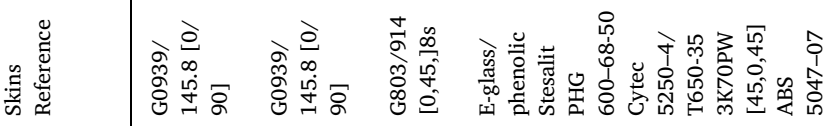

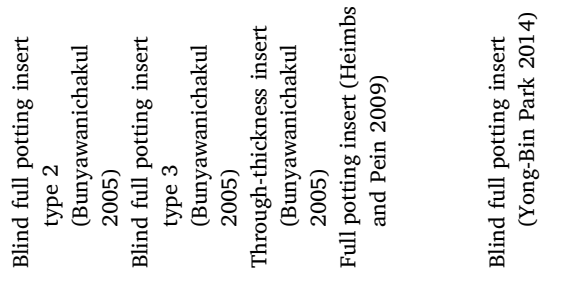




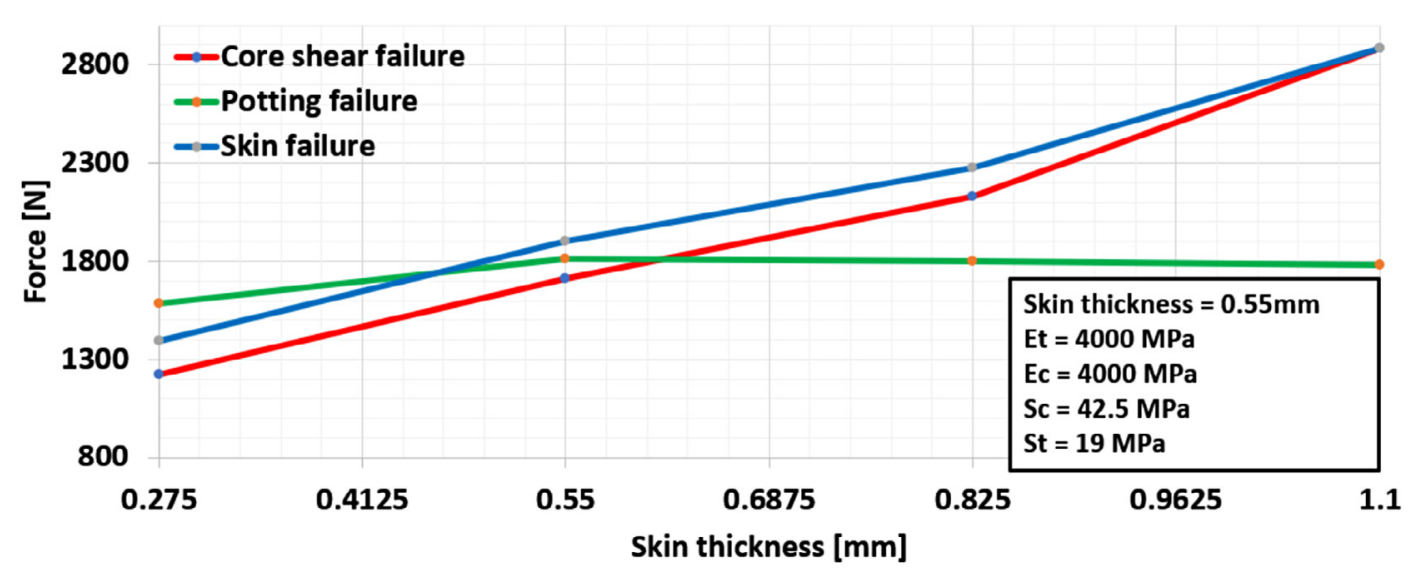

Fig. 16. Failure modes vs thickness of the skins.

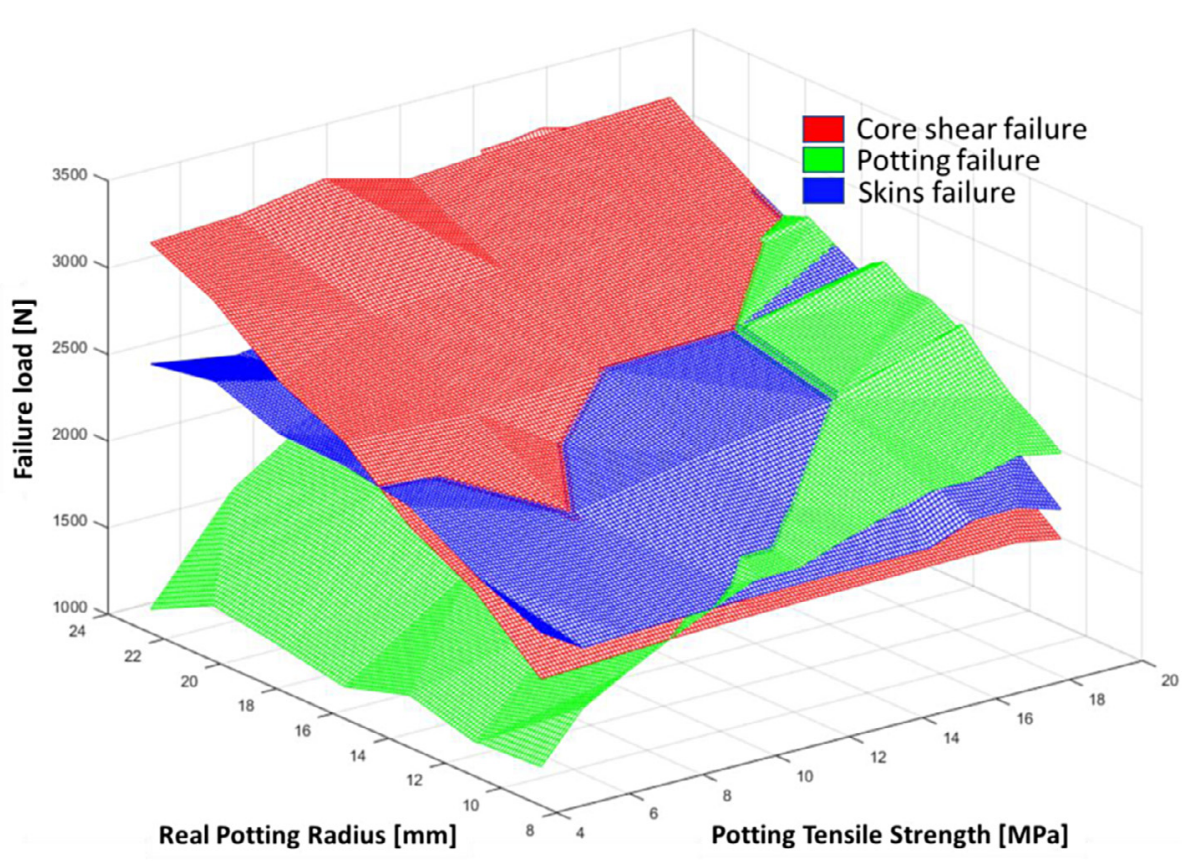

Fig. 17. Failure surfaces of the core, the potting and the skins: RPR vs Potting tensile strength.

technique to reduce time and costs while providing accurate estimations. Nevertheless, the development of a detailed numerical model can take several months, depending on the problem. For this reason, in this research, a simplified numerical model is proposed to plot a failure mode map, which could be an innovative tool to speed up insert sizing.

The first step was to gather the experimental evidence needed for the development of the simplified numerical model. The pull-out tests performed provided solid evidence of the most common damage that can be found for these types of inserts; core shear failure and potting failure as well as the detachment of the potting from the lower skin. Also, it is important to mention that the use of LVDT sensors provided incoherent values for the displacement, while the use of a 3D DIC system was useful to capture the actual displacement applied to the insert. There is evidence suggesting the detaching of the metal insert from the sandwich panel as shown in Fig. 7.

In addition, the experimental evidence suggests that the hypothesis of the RPR is more suitable than the EPR to describe the insert size. This could be the case at least for Nomex honeycomb sandwich panels. The simplified numerical modeling was shown to be useful to detect core shear failure, potting failure and skin failure, in an accurate way and at very low computational cost. Also, this numerical approach allows the nonlinear elastic behavior of the Nomex honeycomb core to be included, by using the approach presented in [32], which is not possible in analytical models. It should be recalled that the skin failure predicted by the numerical model can pass unperceived and it could be important.

The failure mode maps permit the strength of an insert to be observed in a very easy way as a function of the principal design variables, i.e. the size of the potting and the potting material. This tool should be very useful for engineers since it compresses the very accurate results based on F.E. simulations into a simple 2D chart. Also, it has been shown that this failure mode map can be helpful in selecting the best combination of parameters to obtain the best mass to strength ratio. This is easy to see in Fig. 19. The best insert design is the one with the lowest radius and with a potting material selected to resist the required pull-out strength.

\section{Acknowledgments}

The present work was supported in part by the CONACYT from Mexico through the program "Becas Conacyt- Gobierno Frances", the "Institut Clement Ader" and INSA Toulouse. This support is 


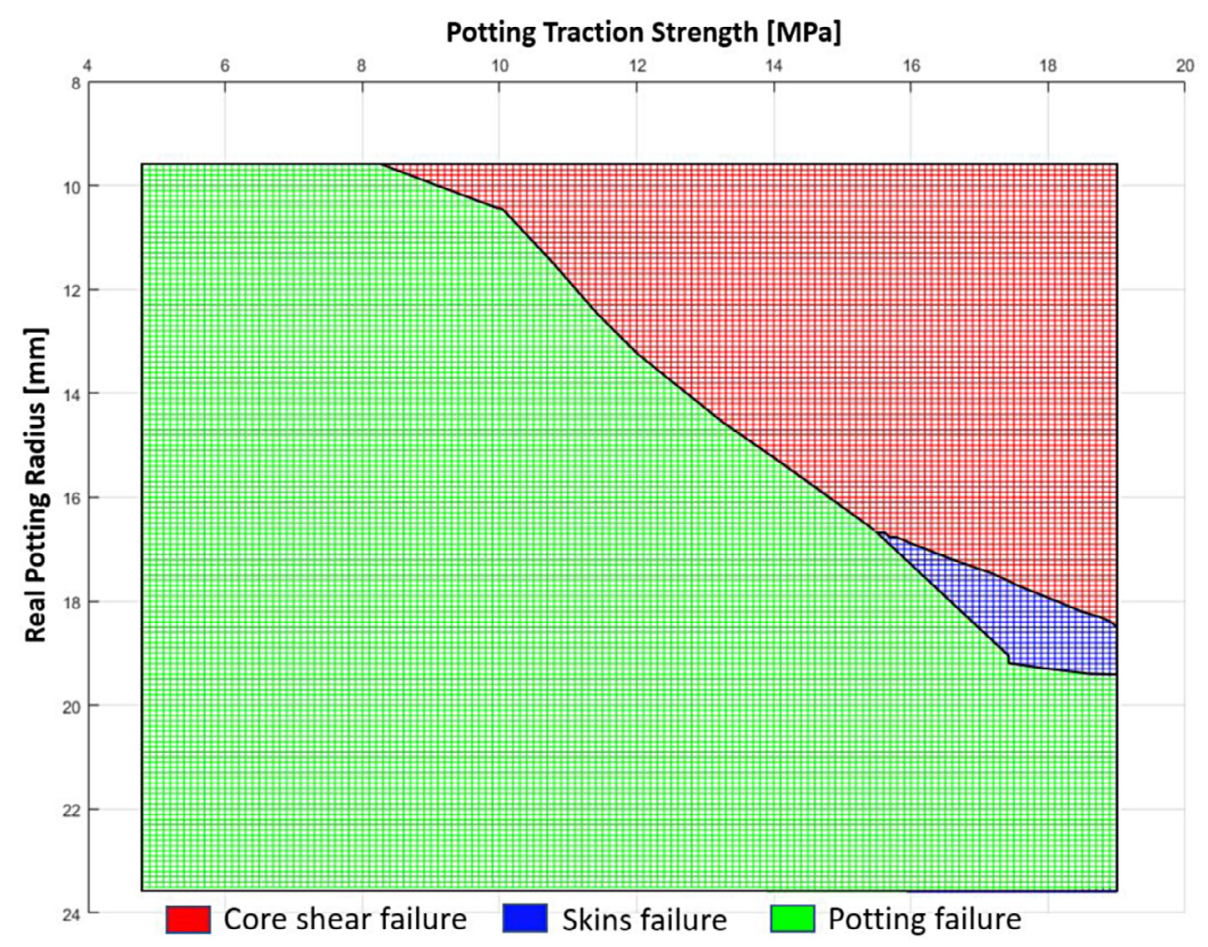

Fig. 18. Failure mode map of inserts: Bottom view of the failure surfaces.

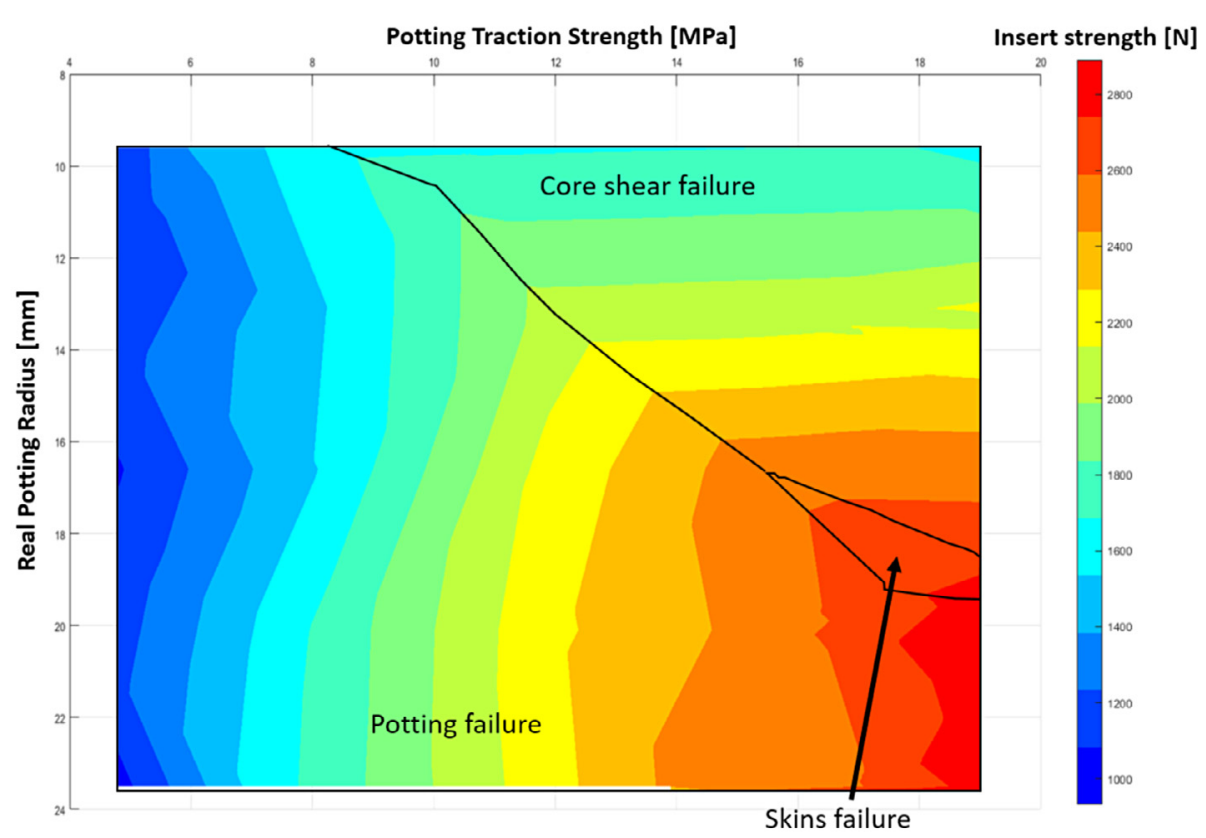

Fig. 19. Failure mode map of inserts with a color scale to identify the failure load.

acknowledged with thanks. The authors are also grateful to Benoît Porra of IMT Mines Albi, and to Matheus Pessanha and Thomas Salomon from INSA Toulouse for their contribution to this work.

\section{References}

[1] Abrate S, Castanié B, Rajapakse YDS. Dynamic Failure of Composite and Sandwich Structures. Netherlands: Springer; 2013.

[2] Hooper EH. Le Starship : un modèle pour les avions futurs. Mat\&Tech 1989;77(6):23-5.

[3] Tomblin SJ, Salah L. Teardown Evaluation of a Composite Carbon / Epoxy Beechcraft Starship Aft Wing. Final report DOT/FAA/TC-15/47, 2017.

[4] Zenkert D. The handbook of sandwich construction. London: Emas; 1997.

[5] Shafizadeh JE, Seferis JC, Chesmar EF, Geyer R. Evaluation of the in-service performance behavior of honeycomb composite sandwich structures. J. Mater. Eng. Perform. 1999;8(6):661-8.

[6] Bunyawanichakul P, Castanié B, Barrau JJ. Experimental and numerical analysis of inserts in sandwich structures. Appl. Comp. Mat. 2005;12(3-4):177-91.

[7] Bozhevolnaya E, Thomsen OT, Kildegaard A, Skvortsov V. Local effects across core junctions in sandwich panels. Comp. Part B Eng. 2003;34(6):509-17.

[8] Thomsen OT. Sandwich plates with 'through-the-thickness' and 'fully potted' inserts: evaluation of differences in structural performance. Comp. Struct. 1997;40(2):159-74.

[9] Ericksen W.S. The Bending of a Circular Sandwich Plate Under Normal Load, Forest Product Laboratory, Report No. 1828, 1953, Madison 5, Wisconsin.

[10] European Cooperation for Space Standardization, ECSS-E-HB-32-22A: Insert Design Handbook, 2011.

[11] US Military Handbook 23A, MIL-HDBK-23A, US Department of Defence 1974.

[12] J. Wolff, M. Brysch, C. Hühne, Pilot study on an analytic sizing tool approach for 
insert load introductions in sandwich elements. Proceeding of ECCM17 Conference, Munich, June 2016.

[13] J. Wolff, F. Trimpe, R. Zerlik, C. Hühne, 2015. Evaluation of an Analytical Approach Predicting the Transversal Failure Load of Insert Connections in Sandwich Structures. Proceedings of ICCM 20, July, Copenhagen.

[14] Seemann RD, Krause D. Numerical modelling of partially potted inserts in honeycomb sandwich panels under pull-out loading. Comp. Struct. 2018;203:101-9.

[15] Bin Park Y, Kweon JH, Choi JH. Failure characteristics of carbon/BMI-Nomex sandwich joints in various hygrothermal conditions. Comp. Part B Eng. 2014;60:213-21.

[16] Heimbs S, Pein M. Failure behaviour of honeycomb sandwich corner joints and inserts. Comp. Struct. 2009;89(4):575-88.

[17] BUNYAWANICHAKUL P. Contribution à l'étude du comportement des inserts dans les structures sandwichs composites PhD Thesis, Supaéro, 2005.

[18] Bunyawanichakul P, Castanié B, Barrau JJ. Non-linear finite element analysis of inserts in composite sandwich structures. Comp. Part B Eng. 2008;39(7-8):1077-92.

[19] Raghu N, Battley M, Southward T. Strength Variability of Inserts in Sandwich Panels. J. Sandw. Struct. Mater. 2009;11(6):501-17.

[20] Roy R, Nguyen KH, Park YB, Kweon JH, Choi JH. Testing and modeling of NomexTM honeycomb sandwich Panels with bolt insert. Comp. Part B Eng. 2014;56:762-9.

[21] P. Kumsantia, B. Castanié, P. Bunyawanichakul, An investigation of failure scenario of the metallic insert in sandwich structures, in: Proceedings of The First TSME International Conference on Mechanical Engineering, Thailand, 2010.

[22] Song KI, Choi JY, Kweon JH, Choi JH, Kim KS. An experimental study of the insert joint strength of composite sandwich structures. Comp. Struct. 2008;86(1-3):107-13.

[23] Adam L, Bouvet C, Castanié B, Daidié A, Bonhomme E. Discrete ply model of circular pull-through test of fasteners in laminates. Comp. Struct. 2012;94(10):3082-91.

[24] Kim BJ, Lee DG. Characteristics of joining inserts for composite sandwich panels.
Comp. Struct. 2008;86(1-3):55-60.

[25] Smith B, Banerjee B. Reliability of inserts in sandwich composite panels. Comp. Struct. 2012;94(3):820-9.

[26] J. Block, T. Brander, K. Marjoniemi, Study on carbon fibre tube inserts Technical Report, Patria, DLR, HUT. Estec Contract, 2004, 16822/NL/PA

[27] Rodriguez-Ramirez JDD, Castanie B, Bouvet C. Experimental and numerical analysis of the shear nonlinear behaviour of Nomex honeycomb core: Application to insert sizing. Comp. Struct. 2018;193:121-39.

[28] Wolff J, Brysch M, Hühne C. Validity check of an analytical dimensioning approach for potted insert load introductions in honeycomb sandwich panels. Comp. Struct. 2018;202:1195-215.

[29] R. Seemann Virtual Testing of Composite Sandwich Structures in Aircraft Interior an Industrial Case Study. Proceeding of ECCM18 Conference. Athens, June, 2018.

[30] R.D. Seemann, D. Krause Numerical modelling of nomex honeycomb cores for detailed analysis of sandwich panel joints. Proceeding of WCCM XI, Barcelona, 2014.

[31] Seemann R, Krause D. Numerical modelling of Nomex honeycomb sandwich cores at meso-scale level. Comp Struct. 2017;159:702-18.

[32] Slimane S, Kebdani S, Boudjemai A, Slimane A. Effect of position of tension-loaded inserts on honeycomb panels used for space applications. Int. J. Interact. Des. Manuf. 2018;12(2):393-408.

[33] J.D.D. Rodríguez-Ramírez, B. Castanié, C. Bouvet, Damage Mechanics Modelling of the shear nonlinear behavior of Nomex honeycomb core. Application to sandwich beams. Mech. Adv. Mater. Struct. In press doi: 10.1080/15376494.2018.1472351.

[34] Triantafillou TC, Gibson LJ. Failure mode maps for foam core sandwich beams. Mat Sci. Eng. 1987; 95:37-53.

[35] Petras A, Sutcliffe MPF. Failure mode maps for honeycomb sandwich panels. Comp. Struct. 1999;44(4):237-52.

[36] Vitale JP, Francucci GJ, Xiong J, Stocchi A. Failure mode maps of natural and synthetic fiber reinforced composite sandwich panels. Comp. Part A 2017;94:217-25.

[37] Andrews EW, Moussa NA. Failure mode maps for composite sandwich panels subjected to air blast loading. Int. J. Impact Eng. 2009;36(3):418-25. 